\title{
Some Observations On The Current Status of Performing Finite Element Analyses
}

\author{
Ivatury S. Raju ${ }^{\mathrm{a}}$ \\ NASA Langley Research Center, Hampton, Virginia \\ Norman F. Knight, Jr. ${ }^{\text {b }}$ \\ Scitor Corp., Reston, Virginia \\ and \\ Kunigal N. Shivakumar ${ }^{\mathrm{c}}$ \\ North Carolina A\&T State University, Greensboro, North Carolina
}

\begin{abstract}
Aerospace structures are complex high-performance structures. Advances in reliable and efficient computing and modeling tools are enabling analysts to consider complex configurations, build complex finite element models, and perform analysis rapidly. Many of the early career engineers of today are very proficient in the usage of modern computers, computing engines, complex software systems, and visualization tools. These young engineers are becoming increasingly efficient in building complex 3D models of complicated aerospace components. However, the current trends demonstrate blind acceptance of the results of the finite element analysis results. This paper is aimed at raising an awareness of this situation. Examples of the common encounters are presented. To overcome the current trends, some guidelines and suggestions for analysts, senior engineers, and educators are offered.
\end{abstract}

\section{Introduction}

Finite Element Analysis (FEA) systems have made astounding progress in advancing the modeling, analysis, and visualization of complex structures and structural components. A few years ago what would have taken an engineer several months to model, analyze, and interpret the results of a sophisticated three-dimensional (3D) model of structural components, the same tasks can now be performed in a few days, thanks to advancements in computer hardware, software, and integration of tools by commercial software developers. Figures 1 and 2 show recent examples of complex models of aerospace structural components (see also references 1-3).

Many of the early career engineers of today are very proficient in the usage of modern computers, computing engines, and complex software packages. These young engineers are becoming increasingly efficient in building complex 3D models of complicated aerospace components. The current day general purpose, commercially available software packages such as NASTRAN, ABAQUS, ANSYS, ADINA ${ }^{\mathrm{d}}$, etc., enable

a NASA Technical Fellow for Structures, NASA Engineering and Safety Center. Fellow AIAA, Member ASME, Member ASCE.

b Principal Subject Matter Expert, Fellow AIAA, Fellow ASME.

c Professor \& Director, Center For Composite Materials Research. Associate Fellow AIAA, Member ASME.

d NASTRAN® is a registered trademark of National Aeronautics and Space Administration, ABAQUS/Standard is a registered trademark of Dassault Systèmes Simulia Corp., ANSYS is trademark of ANSYS, Inc., ADINA is a trademark of ADINA R \& D, Inc. 
sophisticated analyses with 3D complex models very efficiently and rapidly. Post processing and visualization of the results can now be performed with increasingly efficient tools.

The advancements in computing engines and software are allowing users who have little or no background in engineering mechanics to perform analyses and post-process the results of these analyses. As such, the blind acceptance and quality of the interpretation of the results are two significant problems today. This trend is alarming and appears to be worsening. The objective of this paper is to show some of the current trends, identify some of the steps that need to be taken to ensure that this trend is reversed and eliminated, and ensure the usage of good quality FE analysis and results are restored. Guidelines and suggestions for senior engineers and educators are offered. As the practice of finite element analysis is very broad, the scope of this paper is limited to the performance and usage of linear stress analysis tools. Other challenges outside the scope of the current paper include: composite structures requiring careful definition of lamination patterns and local coordinate system definition; thermal stress and strain simulations that often produce non-intuitive solutions; and contact modeling including sliding friction to account for assembly preload that may require the use of unsymmetric equation solvers. For convenience in presentation, the phrases, analysts and engineers, are used interchangeably throughout the paper.

\title{
II. Current Trends
}

\begin{abstract}
"The model exactly looks like the part. The analysis ran to completion without any errors; the results are displayed as contour plots in color - how could the analysis and results be wrong?"- An Analyst
\end{abstract}

Many commercial software developers have tried to build-in a number of checks (such as convergence checks, element size, shape, and type compatibility, etc.) and offer advice, to avoid major pitfalls. However, the use of the tools provided by the software developers and the interpretation of the results are still the purview of the users of the codes. The software developers implicitly assume that the user is familiar with and well versed in engineering and computational mechanics. The current and alarming trends suggest that this assumption may be incorrect and at least some of the users are not well versed in engineering mechanics and the mathematical theories that underlay the finite element method. The following are some of the questions posted on ResearchGate during the past few months:

1. "Validating Curved Composite Panel Results from FEA: I am currently looking at a large, curved, composite panel which is being sized by FEA. Before undertaking a physical test, is there anyone who has experience validating the FEA results for curved panels? Or know of a hand calc method that can accurately predict stresses?" A Professor of Aeronautics and Mechanics replied with a

\footnotetext{
e ResearchGate is a social networking site for scientists and researchers to share papers, ask and answer questions, and find collaborators, Launched in May 2008.
} 
suggestion to look at the fundamentals of shell structures and pointed this person to Timoshenko and Woinowsky-Krieger's book on Plates and Shells (reference $4)$.

2. "Why is it important to have a Weak Formulation for FEM and why it does not give accurate results? What type of method and techniques are available to get accurate results using weak formulation?"

3. "What is the difference between essential boundary conditions and natural boundary conditions?"

4. "What is the shear locking phenomenon and how can we avoid it?"

5. "Why do we always use and plot von Mises stresses in finite element analysis?"

6. "I am writing FEM code for linear buckling analysis of a cylinder shell, but using 3D-solid elements (8-noded-brick element). I am looking for the FEM formula of geometric stiffness matrix (also called stress stiffness matrix or stability coefficient matrix). If everyone has or can derive this formula for 3D-solid element please let me know?"

Clearly, these questions point to the fact the individuals asking these questions have inadequate formal training in engineering mechanics and finite element analysis theory. Admittedly, this is not a sample that points to the current trends. However, some senior professors and the authors have noted similar and alarming trends over the past few years.

In the remainder of this section some of the current trends are discussed.

\section{General Observations}

- General lack of understanding of basic assumptions in engineering mechanics is observed.

- Black box software packages are being used without engineering knowledge about finite element theory and hence, garbage in - garbage out (GIGO) is noticed often.

- The use of building block ${ }^{5}$ approaches in finite element modeling and analysis is very rare.

- A well-thought-out plan to modeling the analysis region is rarely evident.

- Finer meshes where are they are not needed and coarse meshes where large gradients exist are frequently observed, suggesting lack of knowledge of structural and engineering mechanics.

Meshing and Modeling:

One of the authors observed recently, "Meshing is not modeling - Meshing and modeling are two different things." Meshing requires expertise in using a software package, while modeling involves expertise in idealization of the structure and in understanding the structural response to loads and restraints. Current day users are very adept in performing 
quick, rapid, and accurate meshing of complex aerospace structural components. They are adept at meshing but not always at modeling.

Users need to understand the implications associated with selecting one element type over another in terms of the implications of such choices. Choices associated with element shape function order (linear, quadratic, parabolic), element continuity requirements, placement of mid-side nodes, and facetted modeling of curved surfaces do influence the results.

\section{Boundary and interface conditions:}

Often incorrect boundary and interface conditions are prescribed and applied to the models. Also, boundary and interface conditions are chosen to be what is convenient to prescribe and apply. There are also major issues with interpreting the results across the interface regions. Consider a bi-material plate subjected to remote tensile loading as shown in Figure 3. Analysts do not appear to recognize that the interface conditions required to be satisfied are:

$$
\begin{aligned}
& \mathbf{u}^{I}=\mathbf{u}^{I I}, \\
& \left(\sigma_{y}\right)^{I}=\left(\sigma_{y}\right)^{I I}, \\
& \text { and } \\
& \left(\sigma_{x y}\right)^{I}=\left(\sigma_{x y}\right)^{I I}
\end{aligned}
$$

where $\mathbf{u}$ are the displacement fields and $\sigma_{y}$ and $\sigma_{x y}$ are the normal and shear stresses, and the superscripts $I$ and $I I$ denote material $I$ and material $I I$, respectively. As required by the interface conditions in Eq. (1), only the normal and shear stresses are continuous along the interface. However, usually one finds that this fact is ignored and along the bimaterial interface all the stresses are averaged and plots of stress contours are presented.

\section{Three-dimensional (3D) Modeling:}

3D mesh models are currently more common than plate/shell models. The theme appears to be "when in doubt use 3D meshes". Often solid models from ProE ${ }^{\mathrm{f}}$ and/or Solidworks ${ }^{\mathrm{g}}$ are used to develop shape/configuration. These packages treat all geometry as three dimensional. Considerable amount of effort and judgment is required on the part of the analyst to extract representative planes out of the 3D solid model so that accurate shell model representations can be built. Many untrained users are not skilled enough to perform these operations, and hence rely on the use an "Automesh" button even though it may generate a very large number of solid elements to fill a thin plate or a thin shell. The results for bending, transverse shear, and other perhaps important quantities become much harder to interpret from these types of model representations.

\footnotetext{
${ }^{\mathrm{f}}$ PTC Creo, formerly known as Pro/ENGINEER is a parametric, integrated 3D CAD/CAM/CAE solution created by Parametric Technology Corporation (PTC).

g SolidWorks is solid modeling CAD (computer-aided design) software that runs on Microsoft Windows and is since 1997 produced by Dassault Systèmes SolidWorks Corp., a subsidiary of Dassault Systèmes.
} 
Also, combined plate (or shell) and 3D models are very uncommon. The reason for this is that the analysts are not sure what they need to do at the plate /shell and 3D interfaces. Most of the time all the nodes on the interface plane of the 3D model are connected to the plate/shell nodes using a set of kinematic constraints or a rigid body element (RBE) - see text box below - at that interface.

\section{Rigid Body Element (RBE)}

This is the widely used terminology in NASTRAN. In NASTRAN, multipoint constraints are created internally with the rigid elements RBAR, RBE1, RBE2, RBE3. RBE1 defines a rigid body connected to an arbitrary number of GRID points; RBE2 defines a rigid body whose independent degrees of freedom are specified at a single GRID point and whose dependent degrees of freedom are specified at an arbitrary number of GRID points; RBE3 defines the motion at a reference GRID point as the weighted average of the motions at a set of other GRID points (UAI NASTRAN Reference Manual, 1999). Note that all RBEs are rigid. The RBAR and RBE2 do constrain parts to move in total unison as if connected by infinitely stiff structural member. RBE3 and RSPLINE use interpolation relations to calculate the movement of some dependent nodes based on either a weighted average or some polynomial function (spline) of another set of independent points. In these cases the nodes are not locked together and do not move in unison but rather follow along in some average sense. RBAR and RBE2 elements add artificial stiffness to a model. RBE3 does not. Hence modeling with one versus the other can affect load distribution to the connected nodes, modes and dynamic behavior, etc.

Global/Local (G/L) approaches:

Global/Local approaches are used in two situations. The first situation is when after an initial analysis is performed, a region (or regions) of large gradients is identified. The analyst would then like to refine the region of large gradients (local region) alone without changing the modeling in the remainder of the model (global) to obtain a high fidelity solution in the local region. Figure 4 shows two examples of model refinement: global modeling with mesh transition (upper figure) and G/L modeling (lower figure).

The second situation that may require the G/L approach is when two regions of a structure are modeled by two different teams and these two regions need to be connected and analyzed together. An example of this situation is shown in Figure 5, where a global model of the vertical tail and a local model of the lug region were modeled by two different teams and analyzed using two different software packages (see Reference 6).

In both $\mathrm{G} / \mathrm{L}$ approaches, the results of the global model are used to prescribe the conditions across the G/L interfaces, see Figure 6. Clearly, across the G/L boundaries two conditions need to be satisfied ${ }^{1-3,6-11}$ : (a) continuity of displacements and (b) reciprocity of tractions. In most implementations, only the continuity of displacements is prescribed. During the past five years, several types of G/L modeling and analysis variations were observed by the authors:

(a) Displacements from the global model on the $\mathrm{G} / \mathrm{L}$ interface are prescribed at the matching nodes in the local model. Displacements of non-matching nodes are interpolated using some 'average' techniques (see Figure 6). This process 
is repeated for all the faces of the local model in 3D situations or for all edges in $2 \mathrm{D}$ simulations.

(b) The entire face of the local model is constrained using RBEs to a single node and equivalent forces from the global model are prescribed to this node (see Figure 7(a)). This process is repeated for all the faces of the local model in 3D situations (see Figure 7(b)).

(c) The local model is chosen as a convenient rectangular block whose dimensions do not match the local region. The interface process outlined in (b) is followed to prescribe boundary and interface conditions on all the surfaces of the block (see Figure 8).

Obviously, the three strategies outlined above are incorrect and lead to incorrect results and decision making based on these results is not warranted.

\section{Singularities:}

Singularities occur in structural components due to cracks, delaminations, free edges, load discontinuities, material interfaces, etc. Figure 9 shows typical situations that occur in laminated composites. Stresses at these singular point locations have no meaning as the FE solutions do not show convergence. Not recognizing singularities and yet proceeding to perform the analysis is becoming common and structural margins are often reported from analysis using only a single mesh. Clearly, the stress results would change if the mesh is refined near these singularity locations and margins would be different or even negative.

\section{Primary, Secondary and other higher order variables:}

In displacement-based FE analysis the primary variables are displacements. These variables occur in the total potential energy (or virtual work) functional and these variables are the ones analysts obtain from the FE solution. The secondary variables (stresses and strains) are those that are derived by differentiating the primary variables (displacements). As such in a finite element solution, the secondary variables are less accurate than the primary variables ${ }^{1,3}$. In plate bending problems, transverse shear resultants $\mathrm{Q}_{\mathrm{x}}$ and $\mathrm{Q}_{\mathrm{y}}$ - see text box below - derived from the moment equations of equilibrium $^{4}$ are inaccurate ${ }^{1-3}$. Very often analysts appear to be ignoring this issue of accuracy of the secondary and other higher-order variables from the FE analysis and are reporting margins based on these results, which are known to be inaccurate.

\section{Transverse Shear Resultants}

If Kirchhoff plate theory is used, there are no transverse shear strains (plane sections remain plane and are normal to the midplane), and hence transverse shear resultants $\mathrm{Q}_{\mathrm{x}}=\mathrm{Q}_{\mathrm{y}}=0$. However, if one integrates the in-plane equations of equilibrium, one could evaluate the transverse shears and they are accurate. If Mindlin plate theory is used, then the transverse shear strains can be derived from the displacement field approximations. The shear stresses then can be evaluated using the constitutive relationships; however, these shear stresses are inaccurate. To improve the accuracy of the transverse shear stresses, one needs to integrate the in-plane equations of equilibrium. As such, the accuracy of $\mathrm{Q}_{\mathrm{x}}$ and $\mathrm{Q}_{\mathrm{y}}$ from Mindlin formulations can be poor unless one takes extra precautions and determines them by integrating equations of equilibrium ${ }^{12}$. 
Bolts and Bolt Modeling:

Bolts and joints are complex structural configurations. There is no universally accepted process for modeling bolts in the joints. Some typical modeling strategies ${ }^{13}$ for bolted structures include:

1. Simply smearing the thickness of the fastened parts together and ignoring the discrete bolts.

2. Introducing discrete constraints or beam element at every fastener location and ignoring features of the bolt.

3. Including the fastener as one or more beams to simulate the bolt shank with sets of constraints to simulate the bolt head and nut (i.e., beam and spider approach) usually coupled with an explicit model of the fastener hole;

4. Detailed 3D modeling of the bolt head, shank, washer(s), and nut including contact and friction ${ }^{14}$.

In each strategy, the analyst needs to consider the modeling of the parts being fastened together as well as the fastener modeling details. Some of the major bolting issues that are commonly ignored are bolt pretension, friction, and contact. For example, bolt pretension (preload) is not usually included and most analysts lack knowledge of how a preloaded bolted joint works. The preload, can be accounted for by inducing a local strain field in a bar element that represents the bolt (often with an imposed temperature on just those bar elements). This can be difficult to model accurately especially since usually what is specified is bolt torque and not the actual tension value.

As mentioned previously, most analysts prefer 3D modeling throughout the analysis region. While the 3D modeling approach looks easy, complexities associated with contact, friction, interference fits, and preload application make this approach very unreliable. The unreliability stems from the assumptions made for and implementation of friction, contact, and interference. Friction of mating parts is also usually ignored at least in initial analyses. Contact solutions can account for some magnitude of friction but getting the correct distribution is usually a complex and nonlinear behavior that is well beyond most everyday user capabilities. Most analysts appear to be not aware of all these pit falls in bolt modeling and lack knowledge of how a preloaded bolted joint works.

\section{Linear and Nonlinear Analyses:}

Linear analysis is based on small deflections, small rotations, infinitesimal strains, and linear elastic stress-strain law assumptions. The advantages of linear analyses are: simple and direct solutions can be obtained with minimal computational time and effort; solutions can usually be linearly scaled to obtain solutions for a different magnitude of loading; various linear solutions can be superposed (superposition); material constants required to described the constitutive behavior can be kept to a minimum ${ }^{1-3,15-18}$. One can still use advanced complex materials (fully anisotropic) which would have 21 elastic constants but the nonlinearity part of those constants (usually defined in the form of tabulated nonlinear behavior) would not be needed. 
Consider a beam undergoing bending as shown in Figure 10. Linear small deflection analysis implies that $d s \sim d x$ and slopes $(d w / d x)$ are small; $\tan \theta \sim \sin \theta \sim \theta$. When the calculated displacements are higher than half the thickness, the small deflection assumption is no longer valid and nonlinear analysis is needed. Note that from Figure 10, the change in length of the initial differential beam segment $d x$ changes to $d s$. The change in length is then calculated as:

$$
\begin{aligned}
d s^{2} & =d x^{2}+d w^{2} \\
& =\mathrm{dx}^{2} \cdot\left[1+\left(\frac{d w}{d x}\right)^{2}\right] \\
o r & \\
d s & =\mathrm{dx} \cdot\left[1+\left(\frac{d w}{d x}\right)^{2}\right]^{(1 / 2)} \\
& \sim \mathrm{dx} \cdot\left[1+\frac{1}{2}\left(\frac{d w}{d x}\right)^{2}\right]
\end{aligned}
$$

In writing the above equation the cubic and higher-order terms are neglected ${ }^{4}$. When the slope $(d w / d x)$ is not small, the second term in the last equation above indicates that the line segment is being stretched and needs to be accounted for in a large deflection analysis, which makes the analysis geometrically nonlinear.

As mentioned previously, the majority of the present day analyses are linear analyses. Nonlinear analyses are becoming more and more popular due to several reasons ${ }^{15-18}$ : higher performance and light-weight structures are pushing the limits, as such every analyses that takes advantages of all the material and structural efficiencies are being pursued; nonlinear analyses are used to assess continued use of and to expand the capabilities of the structures already in service and extend service life; to identify efficiencies and simulate manufacturing processes of aerospace structural components.

Nonlinearities can be due to material constitutive behavior, geometric deformations, and due to boundary interactions (e.g., contact and friction). Some characteristics of nonlinear analyses are: principle of superposition cannot be applied, only one load case can be applied at a time, solutions are path dependent (i.e., loading sequence is important). In other words, one cannot scale and obtain the solution of a particular load case from a different load case. Also, note that the nonlinear analysis solutions can be non-unique and dependent on solution procedure parameters used to solve the nonlinear algebraic equations.

Nonlinear analyses offer many more opportunities for analysts to misinterpret results and as such one needs to be more vigilant when performing nonlinear analyses. Also, note that many analysts are unaware that different stress and strain measures may crop up in nonlinear geometric analyses. Depending on the element/material combinations $2^{\text {nd }}$ PiolaKirchhoff stresses and Green-Lagrange strains may need to be used ${ }^{3,15-18}$. Often, the analysis tool reports engineering stresses and strains as the default option and analysts need to know and understand what output is provided. 
Inertia Relief ${ }^{19,20}$ :

Software manufacturers have incorporated techniques such as inertia relief to facilitate easy analyses of aerospace components subjected to inertial forces, such as accelerations and gravitational loads. In the conventional inertia relief calculations, reference points or special points are usually chosen where rigid body motions are prescribed. For example, center of gravity of traditional aircrafts is usually chosen as reference support point for inertia relief calculation, for rockets center of gravity or center of buoyancy are usually used for these support location. Support conditions up to six degrees of freedom are needed to remove all rigid body motions and normalize the displacement field. For conventional inertia relief, resultant forces at the reference support node need to be zero (machine zero in the actual computations) for an acceptable solution. Automatic inertia relief is available in some of the software packages. Very often an inertia relief analysis is performed without understanding the theory behind the analysis and the resultant contour plots of displacements and stresses are incorrect. Very frequently, the analysts have failed to perform simple checks to ensure that the presented results did not violate common sense.

\section{Verification and Validation}

Two issues that are overlooked very often today are Verification and Validation (V\&V) of finite element models. Analysis of any physical problem needs to be subjected to $\mathrm{V} \& \mathrm{~V}$. The definitions for $\mathrm{V} \& \mathrm{~V}$ are taken from the NASA Standard on Modeling and Simulation, NASA-STD-7009 (ref. 21). Similar definitions can also be found in references 21-25.

Verification is the process of determining that a computational model accurately represents the underlying mathematical model and its solution i.e. verification is ensuring the computational model is correct in terms of the governing equations (stress, strain, motion) and input data. Verification generally involves two different aspects. One aspect relates to code verification and is primarily the responsibility of the code developer. The other aspect relates to calculation or model verification and is primarily the responsibility of the user.

The code verification activity focuses on identifying and removing errors in the software implementation of the finite element model. Code verification and calculation verification are the two parts of this process. Code verification is often performed by the code and software developers and focuses on making the computer software error free.

Calculation or model verification focuses on the removal of errors introduced during operation and use of the software and is the responsibility of the analysts. Model verification may involve comparisons of highly accurate or exact solutions of a mathematical model and includes an assessment of discretization errors, input data errors, 
and the overall numerical solution of the finite element representation. The analysts need to capture errors due to missing elements, disconnected nodes, improper material assignments, consistency of various coordinate systems, boundary and interface conditions, mechanical, thermal, and inertia loadings, etc. in their models and that the model is appropriate for its intended use. Ensuring that the finite element solution will yield accurate results by successively refining the mesh is a necessary part of this verification activity. In addition, analysts should ensure that the software correctly yields accurate solutions for known problems instead of blindly accepting the general-purpose software without any independent assessment. This can be achieved by running verification problems provided by a software developer and problems for which exact solutions ${ }^{4,26}$ are available. Such a process verifies the tool's function within the analyst's computing environment, verifies the mathematical modeling and idealization process, and provides a check on the analyst's modeling process. This process is referred to as model verification and involves building the model right.

Validation, on the other hand, is the process of determining the degree to which a model is an accurate representation of the real world from the perspective of the intended uses of the model i.e. validation is ensuring the modeling effort captures the physics of the intended application. Validation is the process for testing the model's predictive capabilities of the physical reality being modeled. It has been recommended that validation experiments be designed and performed in concert with the analysis effort to ensure consistent objectives and intended uses of the results extracted from the analysis.

The goal of validation is to increase confidence in the predictive capability of the models. This is achieved by quantifying uncertainties and errors by comparing the results from the computational model to experimental measurements. Validation is application specific, as a model is validated and not the code. The use of building block approaches for testing and analysis is a key aspect of model validation involving the development of higher-level or system models using test-validated models of sub-elements of the structure. Model validation is concerned with building the right model for the intended use of the model.

While most analysts pay little attention to $\mathrm{V} \& \mathrm{~V}$, it is very important to perform verification of all the FE models to the extent possible and validate the model with test data. Figure 2 of Reference 24 discusses in-depth the model V\&V process.

The NASA Standard 7009 (ref. 21) is developed so that the decision makers can rank analyses performed by various analysts and make rational decisions. The standard is new and experience with the use of this standard is limited. It will take a few years for analysts and decision makers to gain experience in actually implementing and using this standard effectively. Various professional societies are working on V\&V (see references 22,23).

\section{Guidelines and Suggestions}


In this section some guidelines and suggestions are offered to the analysts, senior engineers, and educators. These guidelines and suggestions should be useful in avoiding pitfalls discussed in section II.

Most finite element packages offer suggestions in their user manuals to ensure proper use of their software. Some of the general checks are discussed below:

\section{Analysts:}

\section{General Checks:}

- Most FEA packages have distortion checks, and will warn the user if elements exceed those limits. These limits are subjective, and a 'bad' element might not give erroneous results and a 'good' element might not give accurate results.

- Check element normals - all normals need to point in the same direction to ensure proper nodal numbering and to insure the proper application of distributed pressure type loading whose direction is referenced to element normals.

- Use shrink plot to check connectivity and missing elements

- Apply a dummy load which will exercise all components of the model, such as unit inertial loads, solve, and then view displacements to check for mechanisms, spurious constraints and the like.

- Add density and perform a free-free modal analysis. Six rigid body (zero frequency modes) should result. If more or less than of this number occur, the model most likely has mechanisms, and or excessive internal constraints. Mode shapes may reveal places to look for these mechanisms and strain energy summaries may identify areas where internal constraints have developed.

- Large differences in stiffnesses in the same model can cause problems.

- A simple, necessary but not sufficient, test for geometric nonlinearity is to impose the full load and solve the problem as a nonlinear system. If the solution converges in one or two iterations, the structural response is probably linear. If the maximum stresses are lower than the yield stress, then the problem is probably elastic.

Tricks of the trade:

Obtain as much advice as possible from the mentors and educators and learn the tricks of the trade. For example, most experienced analysts know that visualization can be an invaluable tool. However, to capture many trends, one must first ensure that the contour plotting and averaging, which are default setting in most tools, are turned off. With these plots, one can decide on the main features of the solution and decide the regions that need careful scrutiny or remeshing.

\section{Element Selection:}

Numerous elements are available in the general purpose programs. Many elements have issues and do not perform as expected (ref. 1-3, 27-29). Some of the older elements even converge to the incorrect results or convergence to the correct solution is very slow. For example, the 3-node triangular bending element with 9 degrees of freedom (DOF) fails 
the patch test; converges to the incorrect result for an union jack mesh and a load that twists the plate (see reference 1, page 321).

Another example can be illustrated using the widely studied problem of Scordelis-Lo shell roof problem (see Figure 11) under its own weight. This problem was studied by many researchers who were developing shell finite elements ${ }^{27,30-34}$. The vertical displacement at the center of the free edge of the shell roof was used as the figure of merit for comparison. Some results are presented in Figure 12 as a function of the number of DOF in the model (see Reference 27, pages 12 and 13, and page 446 for numerical data). Note that the number of DOF in the model is directly proportional to the computing effort and hence used to compare element performance. As seen from this plot, the accuracy of the elements varies widely and the more recent elements, shown with filled symbols, give accurate displacement results compared to the older elements. Comparison of stress results are not available, but convergence is expected to be slower than for displacements.

There are two paths available for the analysts to ensure that the elements that they wish to use do perform as expected. The first path is to study thoroughly the documentation supplied by the software provider for the elements in the software library. The analysts should ensure the modeling is performed with elements that perform well within reasonable ranges of distortions and element aspect ratios.

The second path is instead of depending on the documentation supplied by the software tool developers, the analysts should develop their own experience database. They should experiment with various element types, mesh configurations, and material combinations apply them to well known classical problems ${ }^{1-4,26,27}$, and study the performance of the elements. Examples of some such problems, MacNeal-Harder problems, can be found in Ref. 28. Fortunately, it is not a difficult job to select few well-performing elements for use and stick with those elements until one finds other good performers to add to one's repository. In addition, analysts should develop their own suite of test cases that are representative of the problem classes they typically model and analyze.

\section{Stress (or Strain) Recovery:}

Frequently, analysts generate contour plots of stress and strain results where the post processing tool averages element values across inter-element boundaries. Most FEA tools do not guarantee continuity of secondary variables such as stresses and strains across inter-element boundaries; however, options are available that result in 'smooth' contour plots. Plotting element values often reveals jumps in these secondary variables indicating that the spatial resolution of the mesh has not converged. In addition, it may be that while some stress component exhibit 'smooth' contours, a different component may not.

To reduce post-processing effort and to ensure that all stress components are considered, 'stress bond' plots ${ }^{35}$ based on un-averaged element stress values have been used to compare different FE solutions and assess mesh convergence. 


\section{G/L approaches:}

Global/local approaches are very useful in obtaining accurate solutions. As mentioned previously, continuity of displacements and reciprocity of tractions need to be maintained across the G/L boundaries. Any of the following strategies can be used to implement the procedure correctly:

(a) Remodel the analysis region with finer mesh over the entire analysis region.

(b) Remodel the region where large gradients exist (local region) with a much finer mesh, and have an interface region that transitions from a finer mesh in the local region to a coarser mesh in the global region (see Figure 4)

(c) Work with the G/L model (as in (b) without a transition region - for example as in Figure 4 lower part) and use the procedures outlined in references 7-11 to perform the analysis with interface methodologies. Most FE software packages provide 2D and 3D interface elements in their element libraries.

(d) Use an iterative procedure outlined in references 6 and 36. These procedures are especially helpful in performing $\mathrm{G} / \mathrm{L}$ analyses when different parts of the models are being analyzed by two different software packages (see reference $6)$.

\section{Bolts and Bolt Modeling:}

Simply smearing the thickness of the fastened parts together and ignoring the discrete bolts or introducing discrete constraints or beam element at every fastener location and ignoring features of the bolt are often adequate to model the overall response of the bolted connection.

The next most common approach used to model mechanically connected parts is to use the beam and spider approach in which the bolt shank is represented as one-dimensional linear elastic beams, while the bolt head, washer(s), and nut are represented as sets of kinematic coupling constraints (RBEs) - see Figure 13. If the fastener is installed with a specified preload, then analysis procedures to impose the preload need to be developed (e.g., use of thermal loading to obtain the preload, certain RBE formulations using Lagrange multipliers that can account for thermal distortion in the element, or some special feature of the analysis tool). The washer-bearing-surface modeling assumptions are discussed in reference 14. Most experienced analysts use ring-type modeling around the bolt hole and discard the stresses in the two rings that are closest to the hole, as the kinematic coupling spider constraints develop spurious stress results in those rings.

In critical bolted connections, the bolt head, bolt shank, washer(s), and the nut are explicitly modeled by 3D elements along with the explicit modeling of the bolt holes. While the 3D modeling approach looks easy, complexities associated with contact, friction, interference fits, and preload application make this approach very unreliable. The unreliability stems from the assumptions made for and implementation of friction, contact, and interference.

Extracting forces from the FE model at the bolt location and then performing hand calculations using classical methods to assess the adequacy of the joint is recommended. 
The stresses from the FE analysis may be artificially high due to concentrated or point loading. Bolt forces can be extracted from the FE results and hand calculations of the local response performed. Analysts need to determine the number of structural members bolted together (e.g., single vs. double lap joint) and assess any load sharing simulated by the FE model.

Shell-3D Regions:

As mentioned previously, there are many instances where it is convenient to model most of the analysis region with plate and shell elements, while regions requiring high-fidelity results are modeled with $3 \mathrm{D}$ elements. However, the difficulty then would be to insure the transitions between these regions are performed correctly. There are many methods used to perform the connections.

(a) Use multipoint constraints to ensure the continuity of displacements and reciprocity of tractions. Figure 14 demonstrates a plate-to-3D connection between nodes $\mathrm{i}$ and $\mathrm{j}$.

(b) The second most popular method is to use RBE elements.

(c) The third method is to use tied constraints that are provided by the software developers. Study the theory manuals of software developers. The developers also explain restrictions and model recommendations. Try out their test cases.

(d) Figure 14(b) demonstrates another method that is simple and easy to implement. In this method, one continues the plate/shell region into the $3 \mathrm{D}$ region for about 2 elements deep. While locally the stresses are inaccurate, one or two thicknesses away the stresses are unchanged compared to those by other methods. As such, this procedure can be used in regions where higher fidelity stresses are not needed.

(e) Another popular method is to use offsets. Figure 14(a) shows all the plate element nodes offset to the top of the 3D region, as in many applications this surface represents the outer mold line.

\section{Stiffener Modeling:}

Aerospace structures are made up of skin-stiffener construction. As such, stiffener modeling is very important. Many variations are available for stiffener modeling by defining appropriate offsets for webs and flanges etc. Figure 15 shows some of these strategies. Each of these procedures needs to be checked out thoroughly and use the checked out procedures consistently.

\section{Senior Engineers and Educators:}

\footnotetext{
“There is nothing so wrong with analysis as believing the answer! Uncertainties appear everywhere When using a mathematical model careful attention must be given to uncertainties in the model ...." Richard Feynman, Appendix F, Vol. II, Rogers Commission Report on Space Shuttle Challenger Accident, Washington, D. C., June 6, 1986.
} 


\section{"One can now make mistakes with more confidence than ever before."......... "Although the finite element method can make a good engineer better, it can make a poor engineer more dangerous" - R. D. Cook, et al. (Reference 1, p. 24)}

Senior engineers and educators consciously need to educate and mentor junior and freshman engineers as a key aspect of their legacy to the engineering profession. Some strategies ${ }^{\mathrm{h}}$ are suggested below:

Courses: Recognize that students need to have strong prerequisite courses such as Strength of Materials, Advanced Strength of Materials, Theory of Elasticity, and Plates and Shells. They also need two FEA theory courses - one basic and another advanced. These courses represent minimum requirements for those performing FEA.

Classical Methods: Teach them and insist that students learn the classical methods. Recognize that it may take a many years to become proficient in these methods. Also, understanding the problems and methods used to analyze and solve these problems will enhance the analysts' ability to ask the right questions at the right time.

Hand calculations: There are many problems that can be solved using classical methods utilizing beam, plate, and shell theories. If there are classical solutions available for a reasonable model of the structure, those classical solutions should be used. Aerospace companies have analysis manuals that capture application of these methods to aerospace structures. The use of classical hand analyses to verify the finite element results is critical. Development of hand analyses, bounding analyses, skills, and tools to need to be taught.

Demonstrate Evaluation of FE results: Develop skills needed to evaluate the results of a FE analysis. Engage them in group discussions of their analyses and results. Teach by example. Recognize that these skills cannot be learned overnight and it will probably take a number of years to become proficient in this endeavor. Modeling is a life-long learning process as the analyst matures and tools advance.

Best Practices: Many textbooks offer many best practices (see reference 1, Chapter 19 and reference 27). Journal papers, conferences, and workshops are other sources for self learning.

\section{Concluding Remarks}

Aerospace structures are complex and are high-performance structures. As such, there is an increased reliance on modeling and analysis and considerable emphasis on accurate

\footnotetext{
$\mathrm{h}$ See also the references quoted in this footnote. The authors came across three excellent presentations/documents that offer invaluable advice: T. Rose, “Your Answers are Wrong!!!”, Presentation to the combined Loads \& Dynamics and Structures NESC Technical Discipline Teams, April 14,2014; L. Procter, "Modal checkout in MSC. NASTRAN", MSC Lunch-n-Learn Series, April 2008; ANSYS: FEABest Practices, Document can be downloaded from: http://innomet.ttu.ee/martin/MER0070/Loengud/FEA_Best_Practices.pdf
} 
analyses of these structures. Advances in reliable and efficient computing and modeling tools are enabling analysts to model complex three dimensional (3D) configurations and perform analysis rapidly and efficiently. Many of the early career engineers of today are very proficient in the usage of modern computers, computing engines, and complex software and visualization tools. However, the current trends also suggest that there is blind acceptance, at many levels, of the results of the finite element analysis. There appears to be a general lack of understanding of basic assumptions in engineering mechanics. The current day analysts are adept at meshing but not developing a wellthought-out plan for modeling and analysis. Most of the pitfalls are observed in arriving at proper boundary and interface conditions, in regions of plate/shell interfaces, singularities, and bolts and bolt modeling. Improper use of primary and secondary variable results, linear and nonlinear analyses and inertia relief methods are also frequently observed.

To overcome these trends guidelines and suggestions are offered to analysts, senior engineers, and educators. Analysts need to study software developers' manuals, actively pursue verification and validation of their finite element models, experiment with various elements to develop their own library of elements with good performance characteristics. Senior engineers and educators need to ensure that the young engineers receive proper grounding in classical methods, finite element theory, simple yet bounding models, hand calculation techniques, and methods for evaluating finite element results.

\section{References}

${ }^{1}$ Cook, R. D., Malkus, D. S., and Plesha, M. E., Concepts and Applications of Finite Element Analysis, Third Edition, John Wiley \& Sons, 1989.

${ }^{2}$ Zienkiewicz, O. C. and Taylor, R. L., The Finite Element Method, Vols. 1 and 2, Fourth Edition, McGraw Hill Publishers, 1989.

${ }^{3}$ Bathe, K. J., Finite Element Procedures, Prentice-Hall, Englewood Cliffs, NJ, 1996.

${ }^{4}$ Timoshenko, S. P. and Woinowsky-Krieger, S., Theory of Plates and Shells, $2^{\text {nd }}$ Edition, McGraw-Hill Book Company, New York, 1959.

${ }^{5}$ Raju, I. S., Knight, N. F., Jr., Song, K., and Phillips, D. R., “Fracture Mechanics Analyses of the Slip-Side Joggle Regions of Wing-Leading-Edge Panels", Frattura ed Integrità Strutturale, Vol. 15, 2010, pp. 35-49.

${ }^{6}$ Raju, I. S., Glaessgen, E. H., Mason, B. H., Krishnamurthy, T., and Davila, C. G, "Structural Analysis of the Right Rear Lug of American Airlines Flight 587", Computer Modeling in Engineering and Sciences, Vol. 22, pp.1-30, 2007. 
${ }^{7}$ Aminpour, M. A., Ransom, J. B., and McCleary, S. L., “A Coupled Analysis for Structures with Independently Modeled Finite Element Subdomains," International Journal for Numerical Methods in Engineering, Vol. 38, 1995, pp. 3695-3718

${ }^{8}$ Ransom, J. B., McCleary, S. L., and Aminpour, M. A., “A New Interface Element for Connecting Independently Modeled Substructures," AIAA Paper No. 93-1503, Proceedings of the AIAA/ASME/ASCE/AHS/ASC $34^{\text {th }}$ Structures, Structural Dynamics, and Materials Conference, 1993, pp. 1693-1703.

${ }^{9}$ Ransom, J. B., "Interface Technology for Geometrically Nonlinear Analysis of Multiply Connected Subdomains," AIAA Paper No. 97-1298, Proceedings of the AIAA/ASME/ASCE/AHS/ASC $38^{\text {th }}$ Structures, Structural Dynamics, and Materials Conference, 1997, pp. 1862-1872 .

${ }^{10}$ Ransom, J. B. and Knight, N. F., Jr., "Global/Local Stress Analysis of Composite Panels," Computers and Structures, Vol. 37, No. 4, 1990, pp. 375-395.

${ }^{11}$ Farhat, C. and Roux, F. X., "A method of finite element tearing and interconnecting and its parallel solution algorithm", International Journal for Numerical Methods in Engineering, Vol. 32, 1991, pp. 1205-1228.

${ }^{12}$ Hartman, T. B., Hyer, M. W., Case, S. W., " Stress Recovery in Composite Laminates", Paper presented at the 52nd AIAA/ASME/ASCE/AHS/ASC Structures, Structural Dynamics and Materials Conference, Denver, Colorado, AIAA Paper No. 2011-1856, April 2011.

${ }^{13}$ Kim, J., Yoon, J.-C., and Kang, B.-S., "Finite element analysis and modeling of structures with bolted joints," Applied Mathematical Modeling, Vol. 31, pp. 895-911, 2007.

${ }^{14}$ Knight, N. F., Jr., Phillips, D. R., and Raju, I. S., "Simulating Structural Response of a Preloaded Bolted Joint," Paper presented at the $49^{\text {th }}$ AIAA/ASME/ASCE/AHS/ASC Structures, Structural Dynamics and Materials Conference, Schaumburg, Illinois, AIAA Paper No. 2008-1842, April 2008.

${ }^{15}$ Hinton, E. (Ed.), NAFEMS: Introduction to Nonlinear Finite Element Analysis, NAFEMS, Glasgow, UK, 1992.

${ }^{16}$ Crisfield, M. A., Nonlinear Finite Element Analysis Of Solids And Structures, Volume 1, John Wiley \& Sons, Chichester, 1991.

${ }^{17}$ Reddy, J. N., An Introduction to Nonlinear Finite Element Analysis, Oxford University Press. New York, 2004.

${ }^{18}$ Belytschko, T., Liu, W. K., Moran, B., and Elkhodary, K. I., Nonlinear Finite Elements for Continua and Structures, Second Edition, John Wiley \& Sons, 2013. 
${ }^{19}$ Barnett, A. R., Wildrick, T. W., and Ludwiczak, D. R., "Closed-form static analysis with inertia relief and displacement-dependent loads using a MSC/NASTRAN DMAP Alter", 1995 World User's Conference, MacNeal-Schwendler Corporation, Los Angeles, CA, May 8-12, 1995, Also available as NASA TM 106836, Jan. 1995.

${ }^{20}$ Liao, L., "A study of inertia relief analysis", Paper presented at the 52nd AIAA/ASME/ASCE/AHS/ASC Structures, Structural Dynamics and Materials Conference, Denver, Colorado, AIAA Paper No. 2011-2002, April 2011.

${ }^{21}$ Anonymous, NASA Standard for Models and Simulations, NASA-STD-7009, National Aeronautics and Space Administration, Washington, D.C., July 2009.

${ }^{22}$ Anonymous, AIAA, Guide for the Verification and Validation of Computational Fluid Dynamics Simulations, American Institute of Aeronautics and Astronautics, AIAA-G-077- 1998, Reston, VA, 1998.

${ }^{23}$ Anonymous, ASME, Guide for the Verification and Validation of Computational Solid Mechanics, American Society of Mechanical Engineers, ASME-V\&V-10-2006, New York, 2006.

${ }^{24}$ Thacker, B. H., "The Role of Nondeterminism in Verification and Validation of Computational Solid Mechanics Models", Society of Automotive Engineers, Paper 2003-01-1353, 2003.

${ }^{25}$ Roache, P. J., Verification and Validation in Computational Science and Engineering, Hermosa Publishers, Albuquerque, NM, 1998.

${ }^{26}$ Timoshenko, S. P. and Goodier, J. N., Theory of Elasticity, McGraw-Hill Book Company, 1970

${ }^{27}$ MacNeal, R. H., Finite Elements: Their Design and Performance, Marcel Dekker, Inc., 1994.

${ }^{28}$ MacNeal, R. H., and Harder, R. L., "A Proposed Standard Set of Problems to Test Finite Element Accuracy," Finite Elements in Analysis and Design, Vol. 1, 1985, pp. 3-20.

${ }^{29}$ Sun, E. Q., "Shear Locking and Hourglassing in MSC Nastran, ABAQUS, and ANSYS," Paper 27. Presented at the MSC Software Virtual Product Development Conference, (VPD 2006), Huntington Beach, CA., July 17-19, 2006.

${ }^{30}$ Strickland, G. E., and Loden, W. A., “A Doubly-Curved Triangular Shell Element”, Proc. 2nd Conf. on Matrix Methods in Structural Mechanics, Wright-Patterson AFB, Ohio, 1968.

${ }^{31}$ Bonnes, G., Dhatt, G., Gironn, Y. M., and Robichand, P. A., "Curved Triangular 
Elements For The Analysis Of Shells", Proc. 2nd Conf on Matrix Methods in Structural Mechanics, Wright-Patterson AFB, Ohio, 1968.

${ }^{32}$ Clough, R. W., and Johnson, R. L., “A Finite Element Approximation For The Analysis Of Thin Shells”, Int. Jnl. Solids and Structures, Vol. 4, 1968, pp. 43-60.

${ }^{33}$ Cowper, G. R., Lindberg, G. M., Olson, M. D., “A Shallow Shell Finite Element of Triangular Shape”, Int. Jnl. Solids Structures, Vol. 6, 1970, pp. 1133-1156.

${ }^{34}$ Raju, I. S., Venkateswara Rao, G., Prakasa Rao, B., and Venkataramana, J., “A Conical Shell Finite Element”, Computers and Structures, Vol. 4, 1974, pp. 901-915.

${ }^{35}$ Sussman, T., and Bathe, K. J., "Studies of Finite Element Procedures - Stress Band Plots and the Evaluation of Finite Element Meshes", Engineering Computations, Vol. 3, Sep 1986, pp. 178-191.

${ }^{36}$ Whitcomb, J. D., and Woo, K., "Application of Iterative Global/Local Finite Element Analysis. Part 1: Linear Analysis, Part 2: Geometrically Non-Linear Analysis", Communications in Numerical Methods in Engineering, Vol. 9, 745-756 (Part 1), 757-766 (Part 2), 1993. 


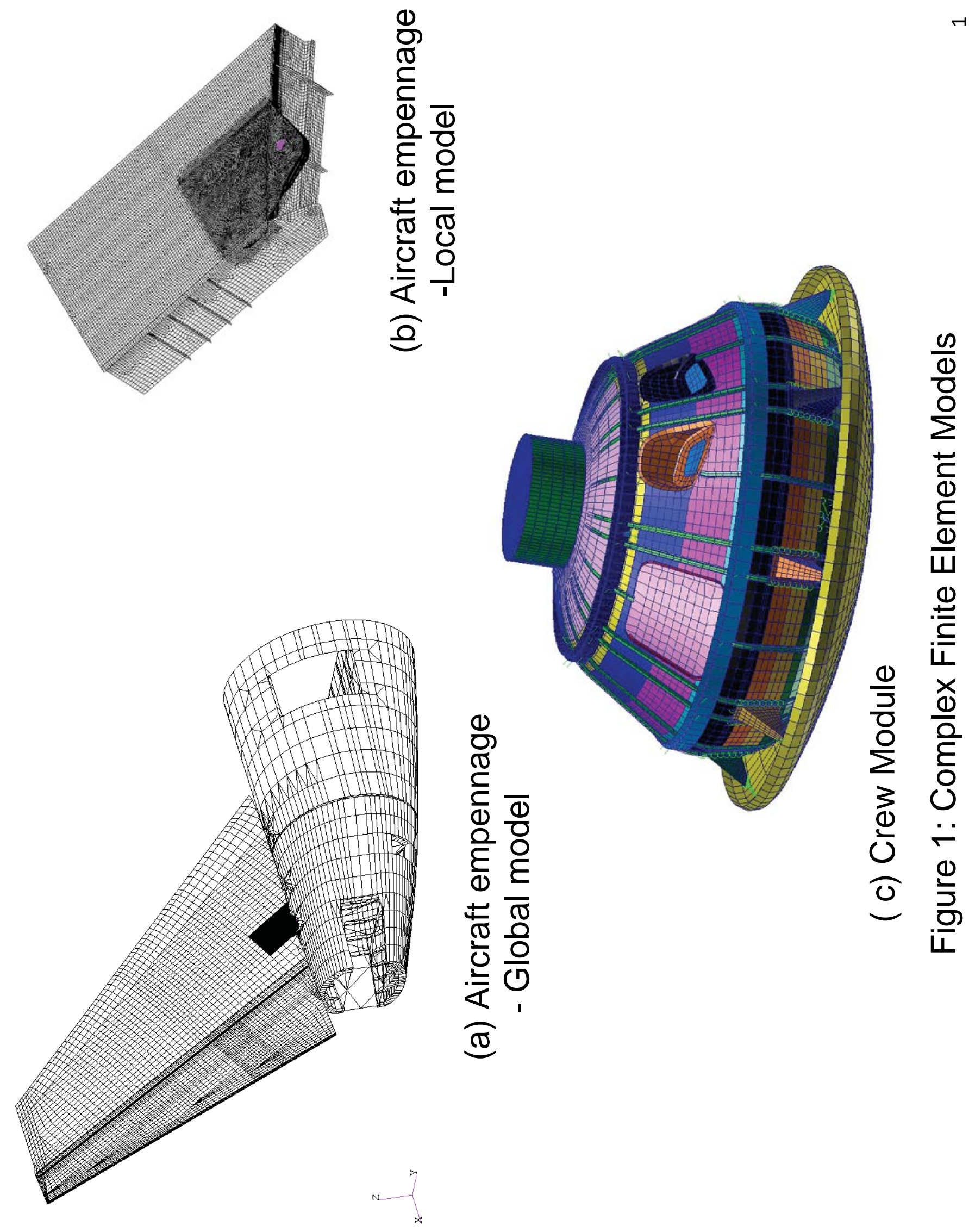



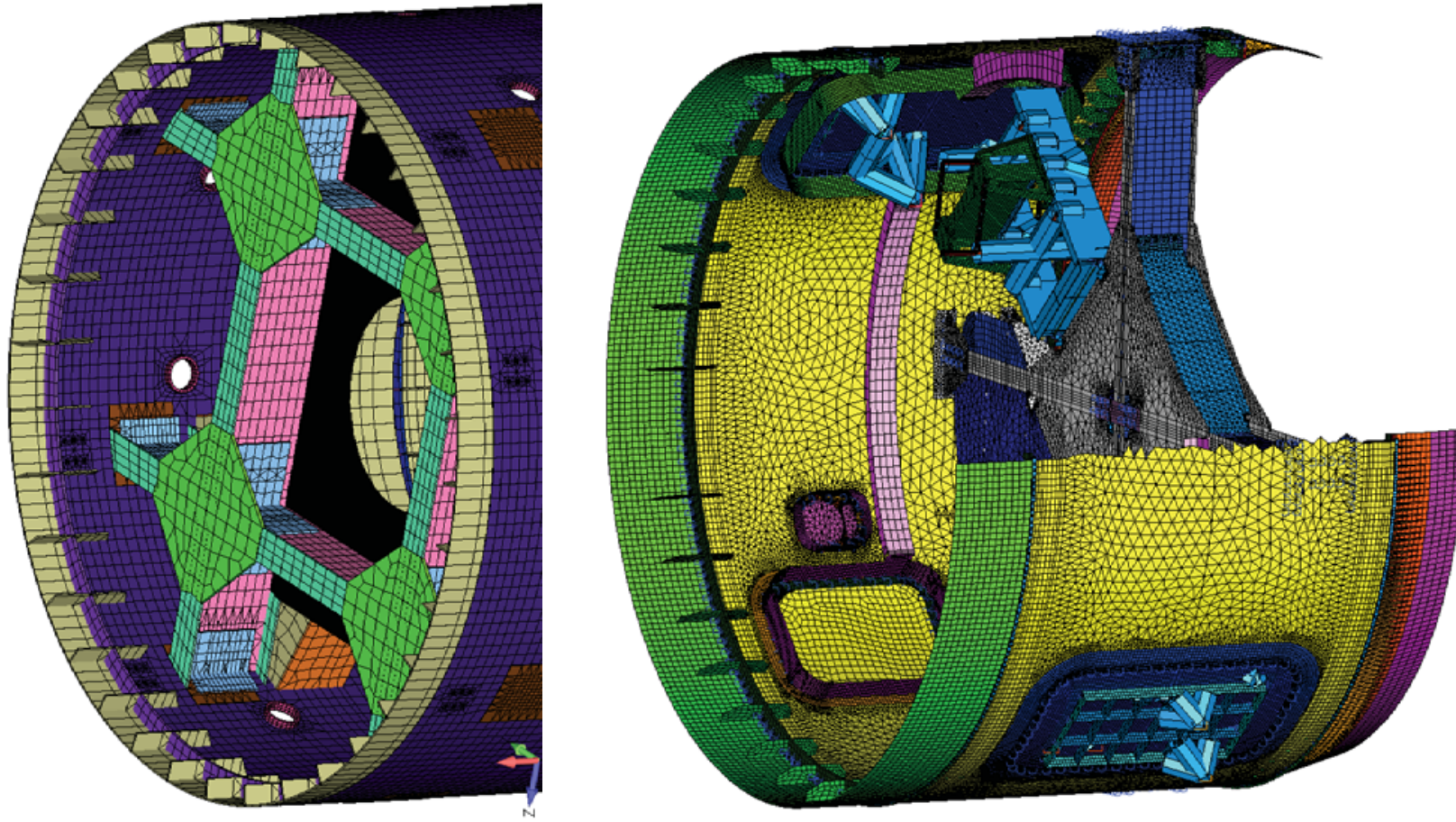

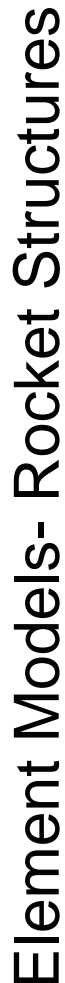
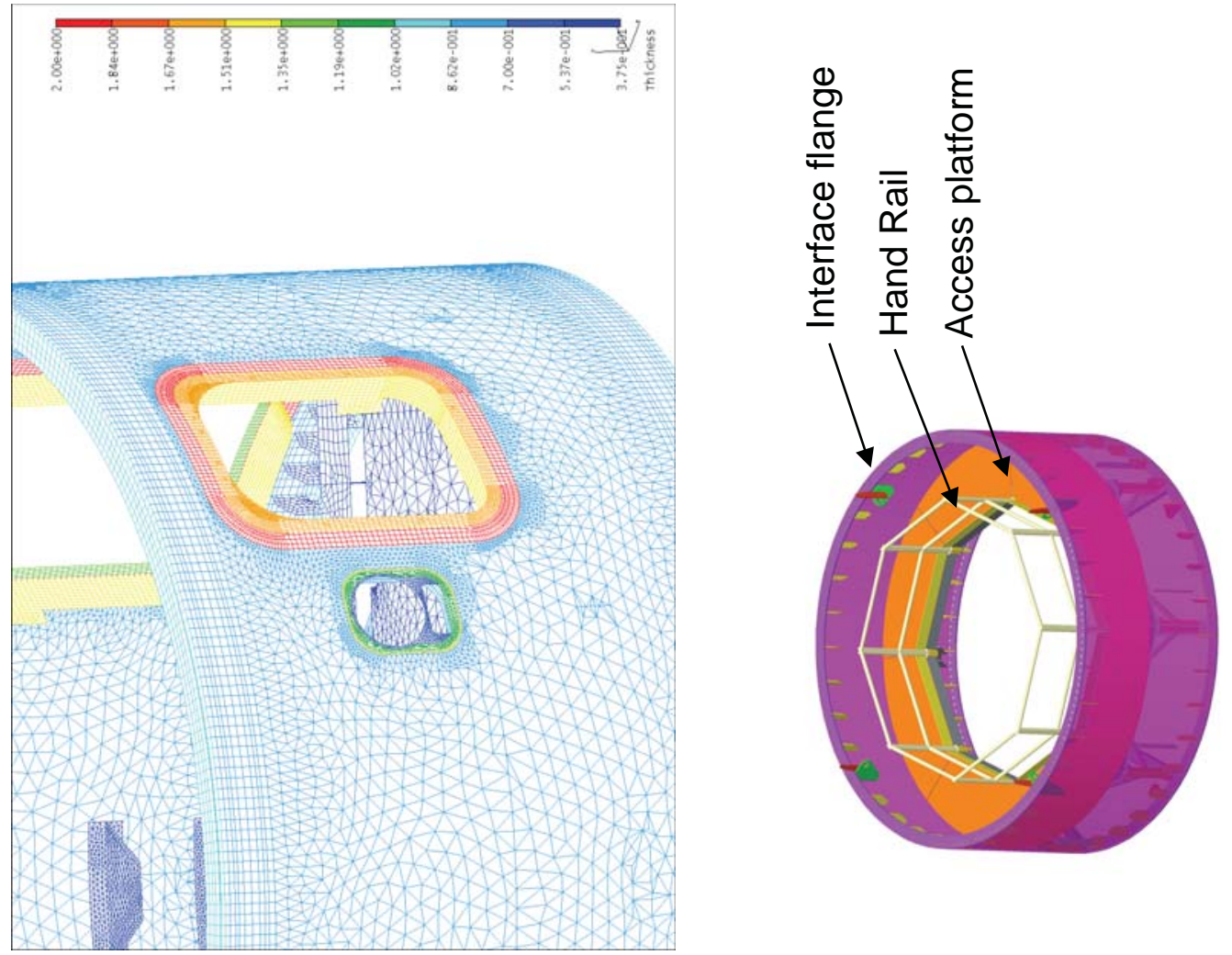

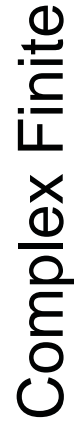

ì

음 


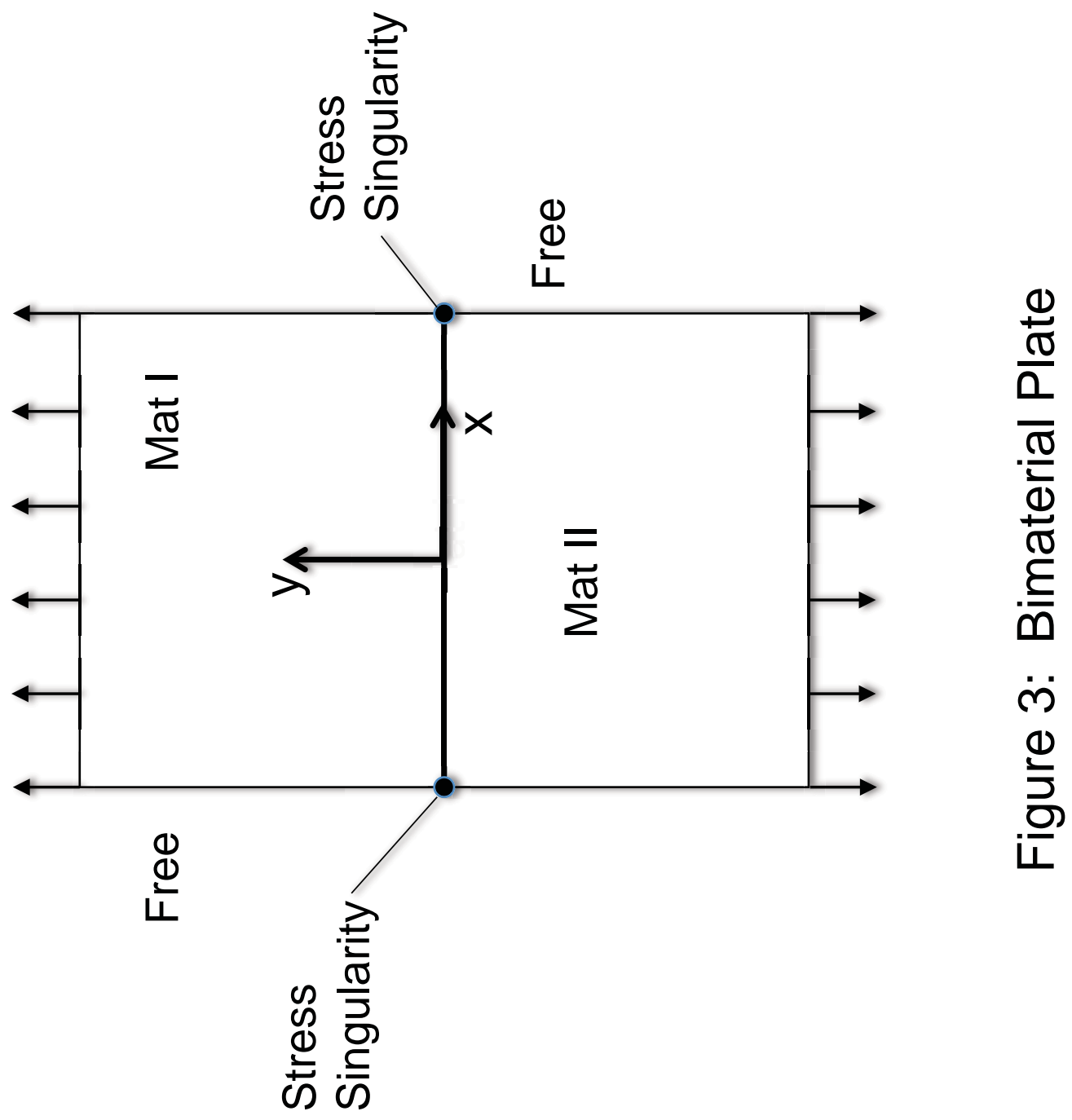




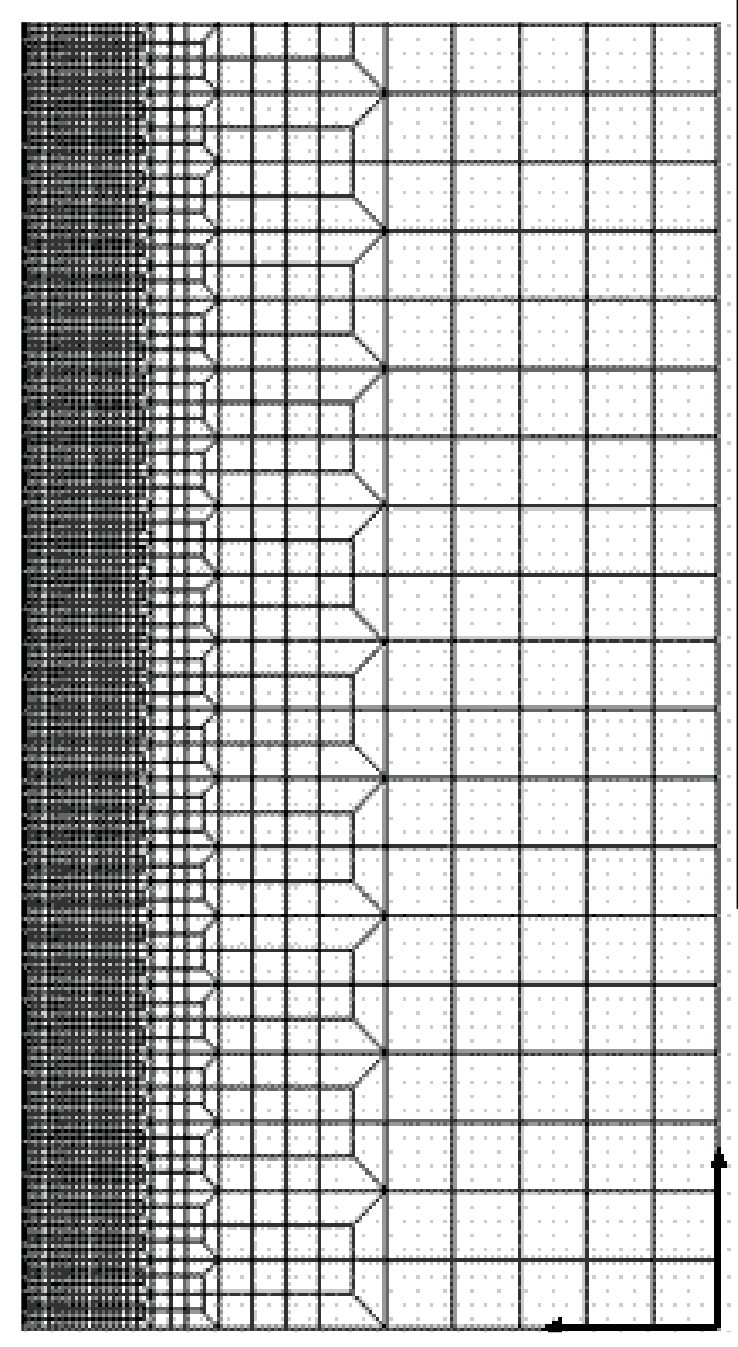

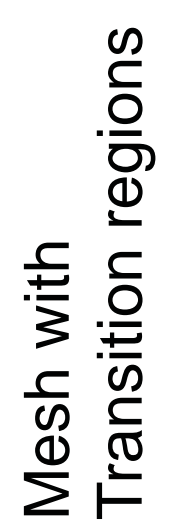
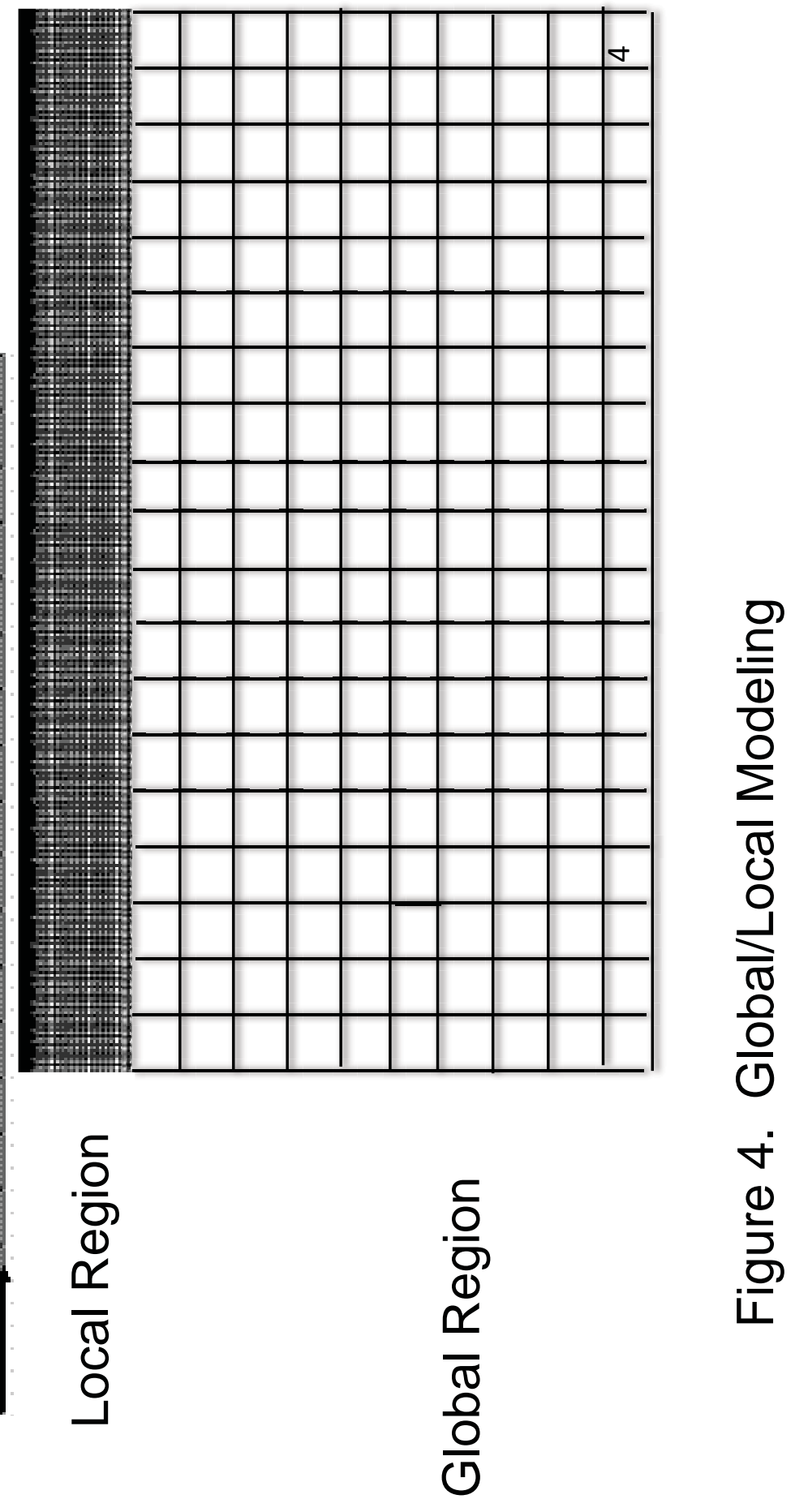


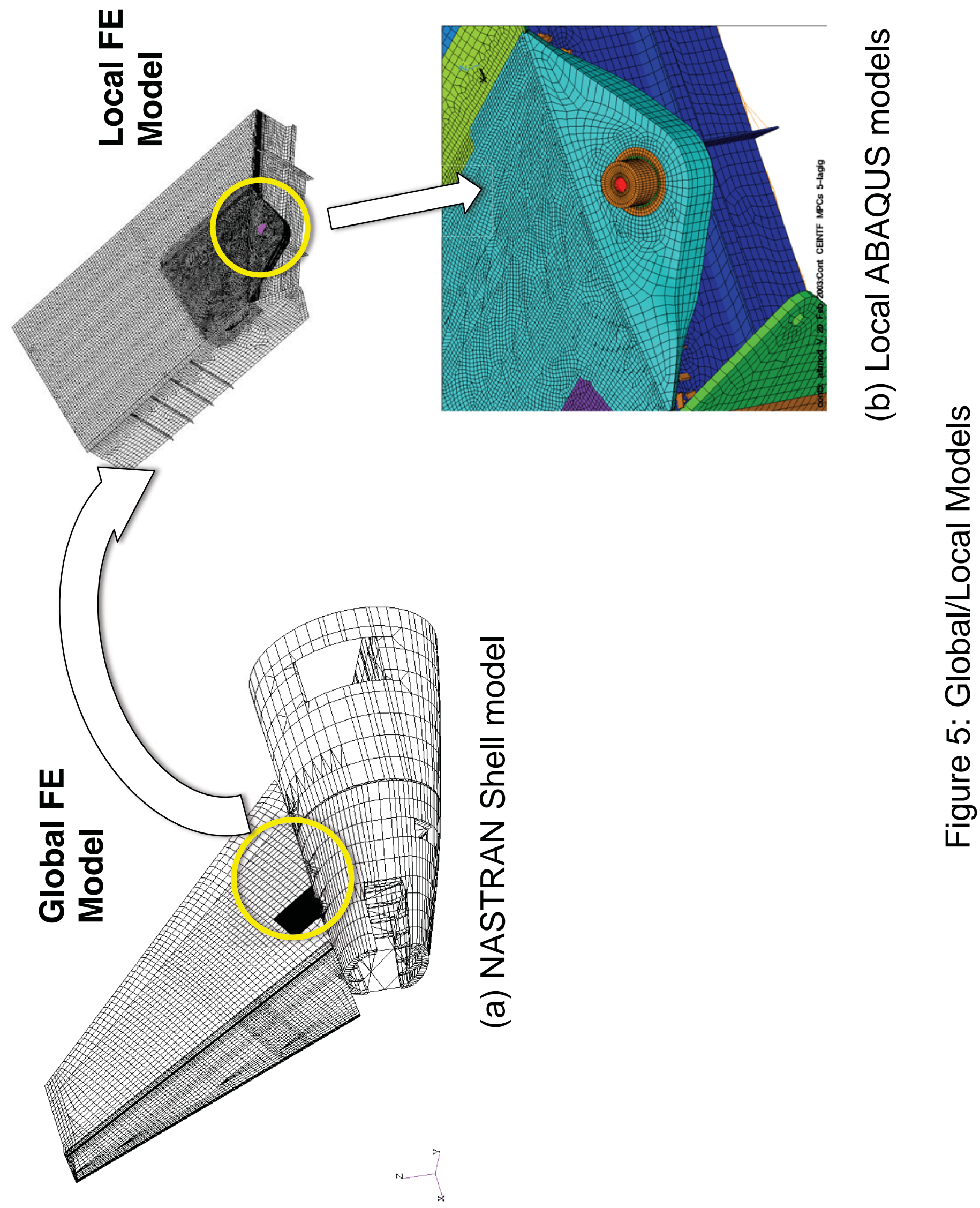




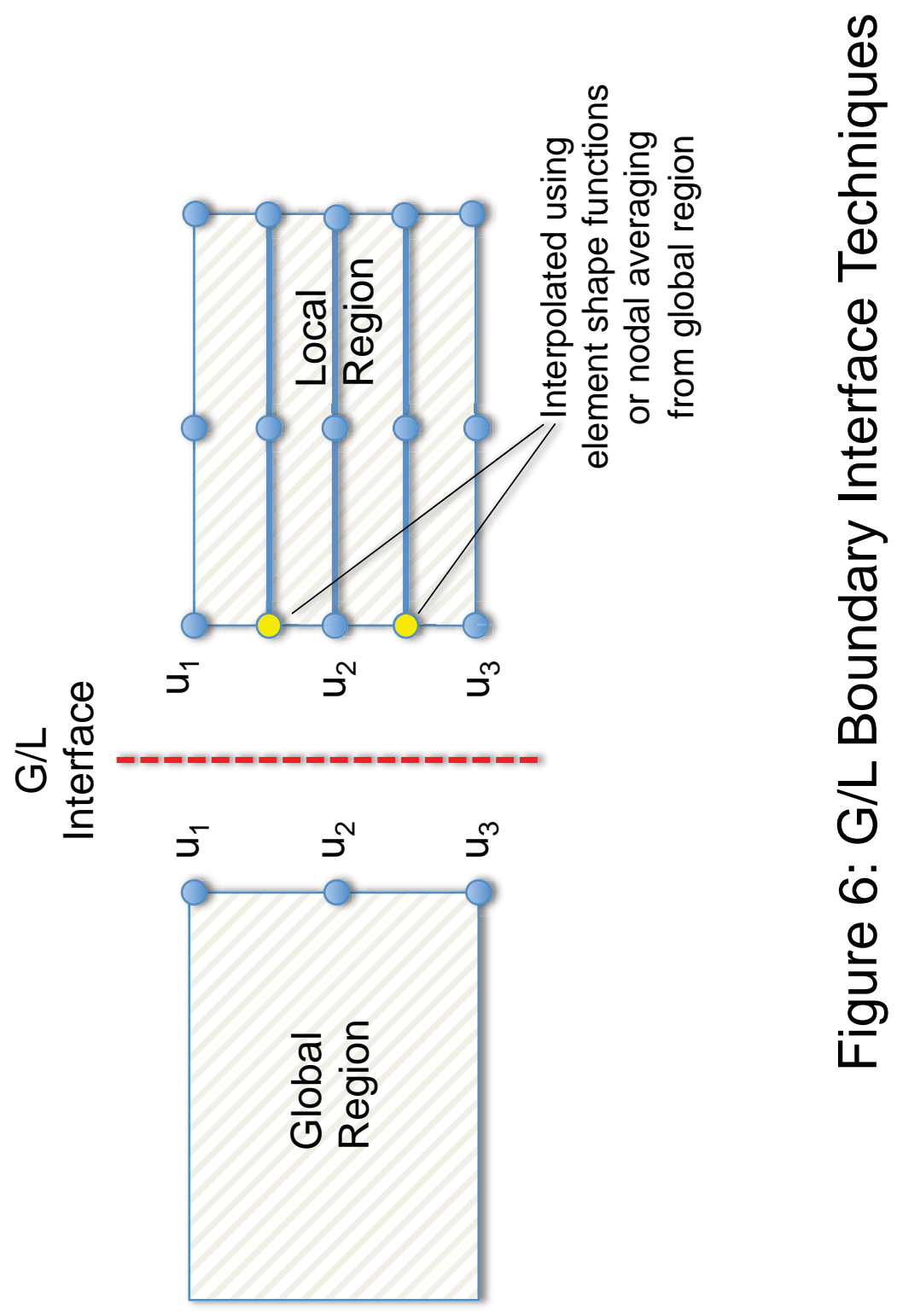



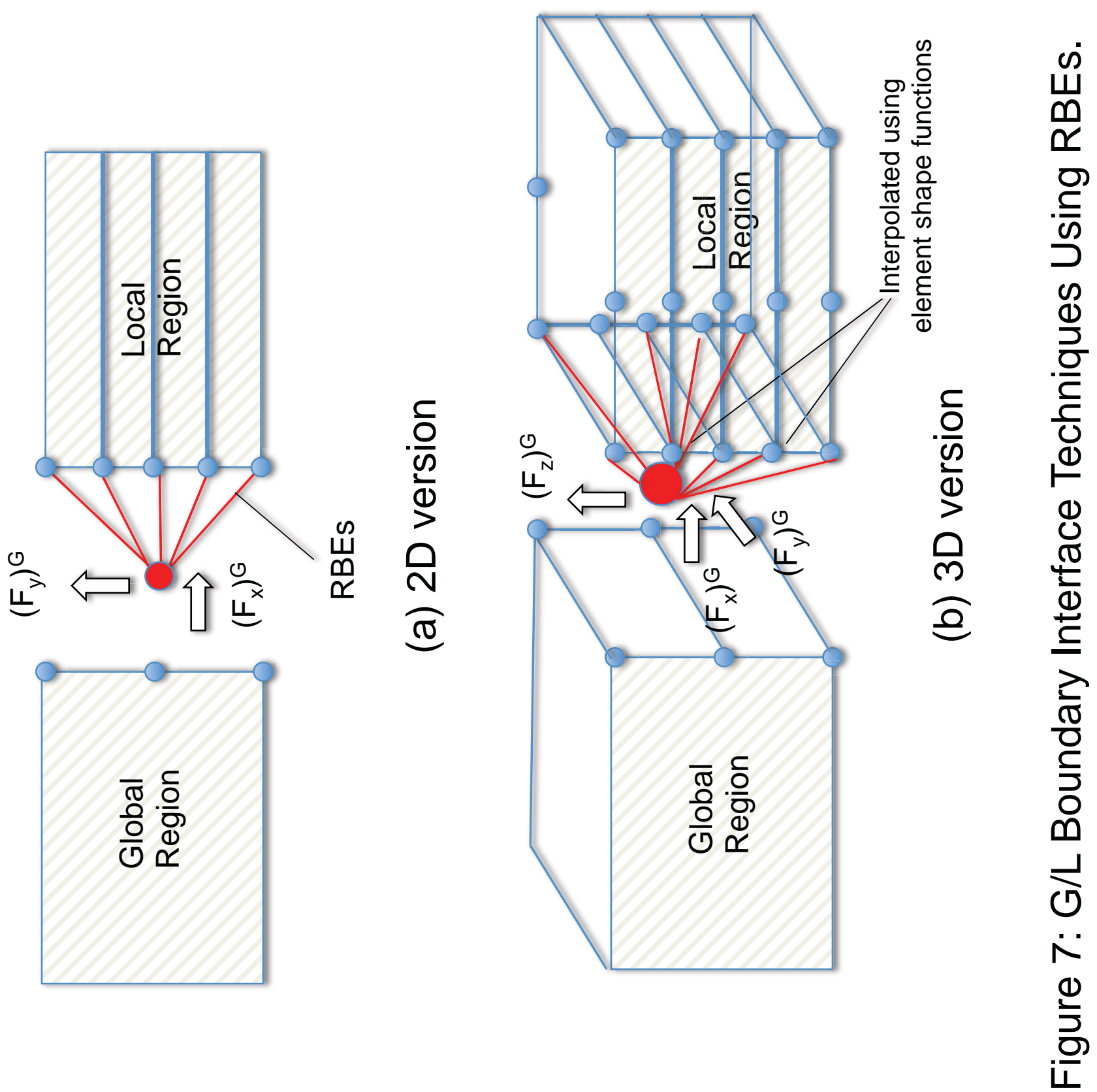


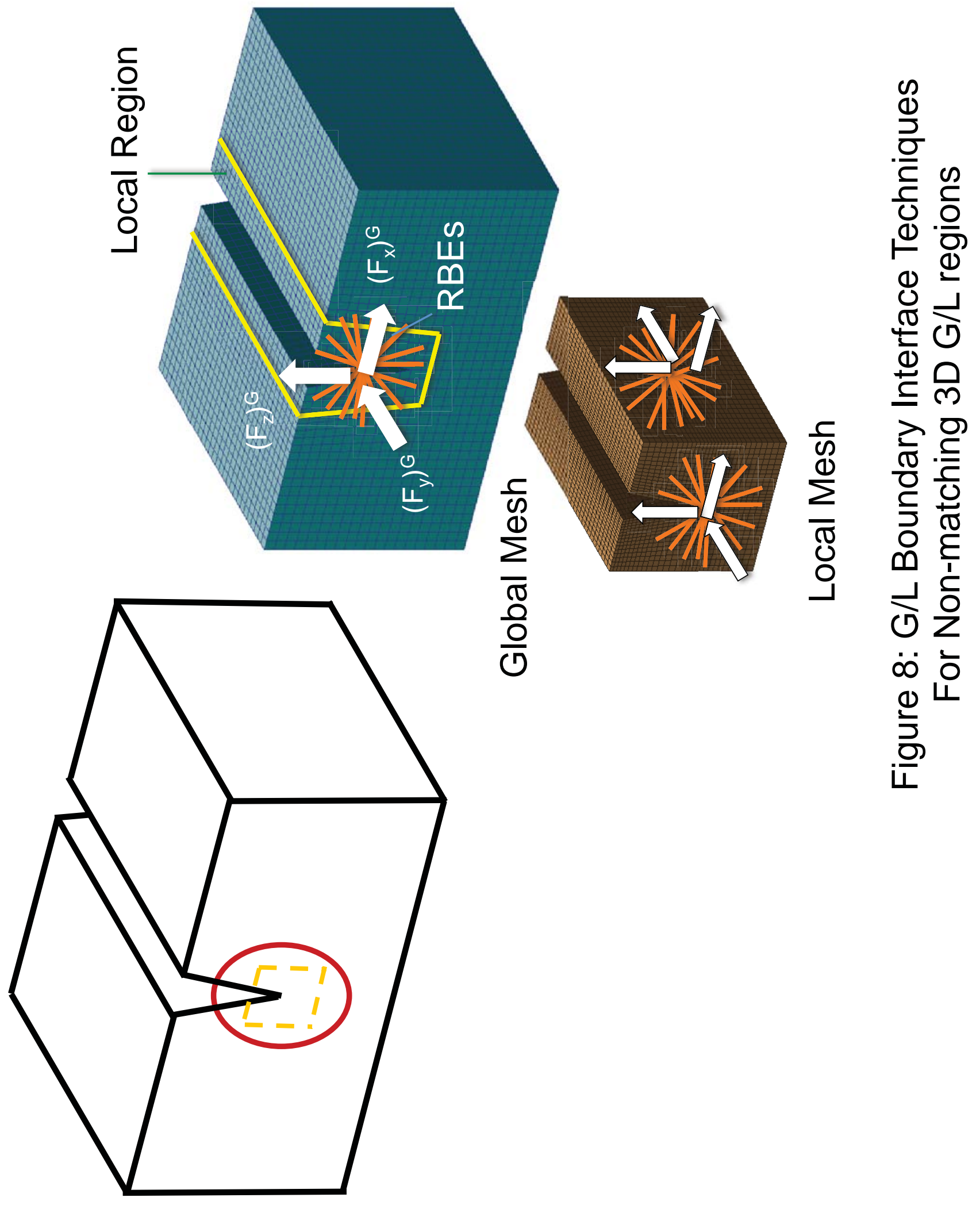




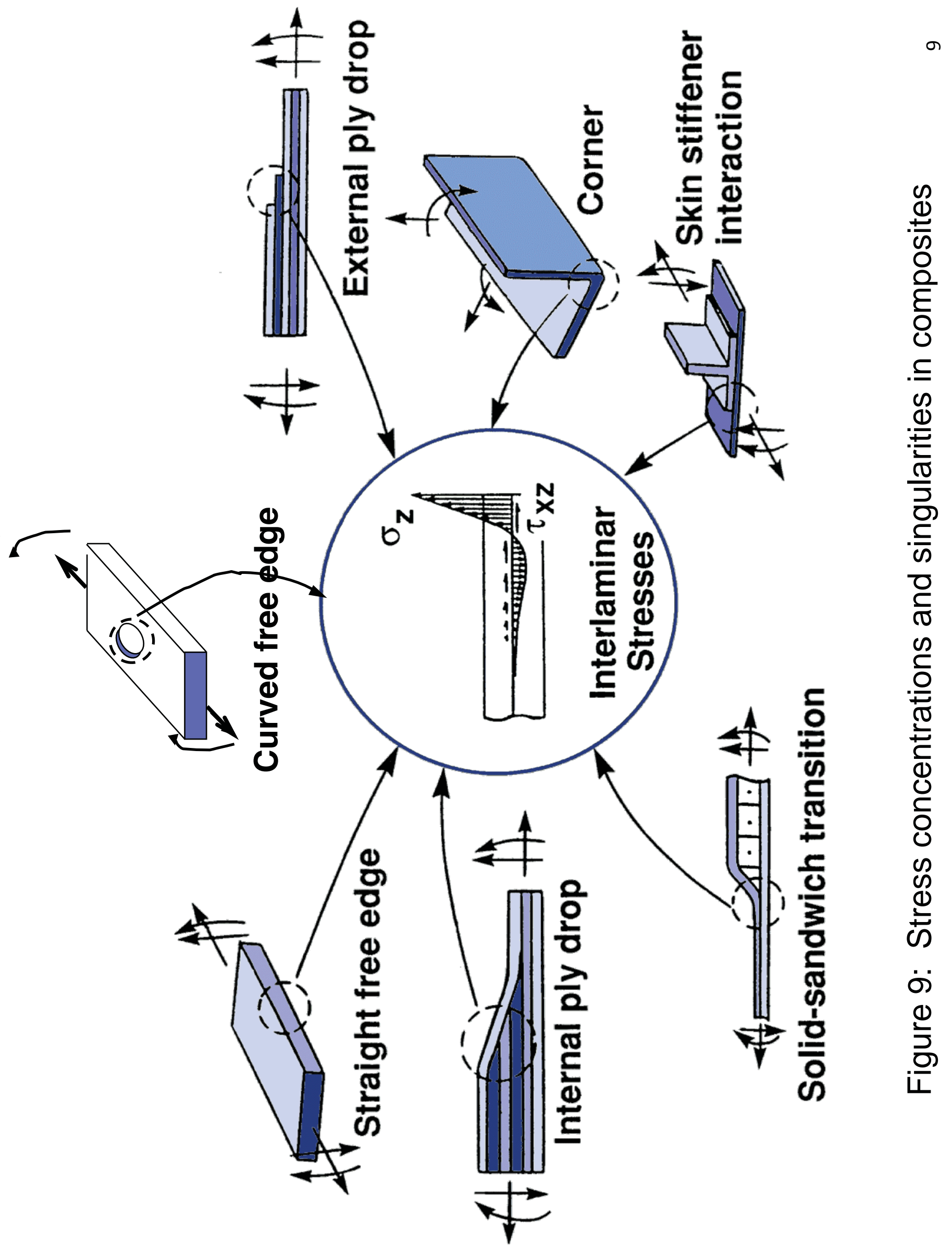




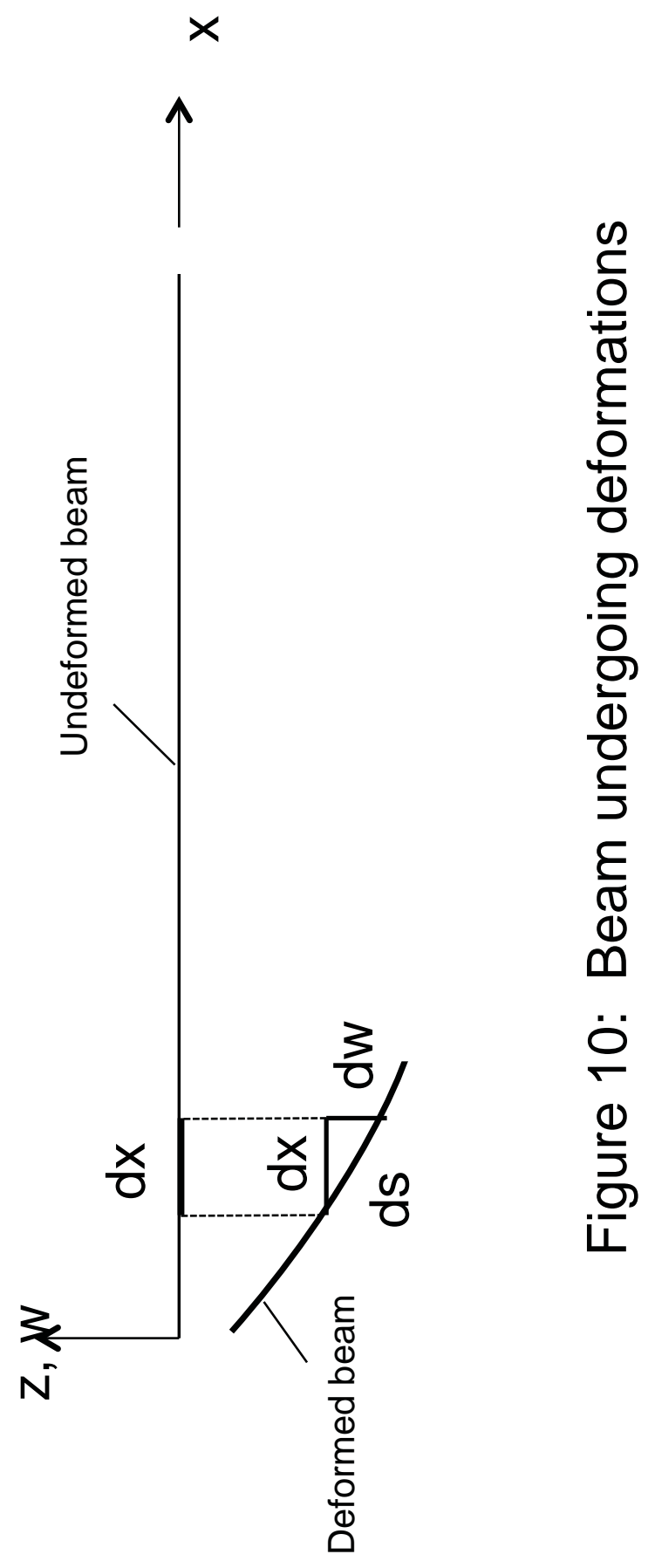



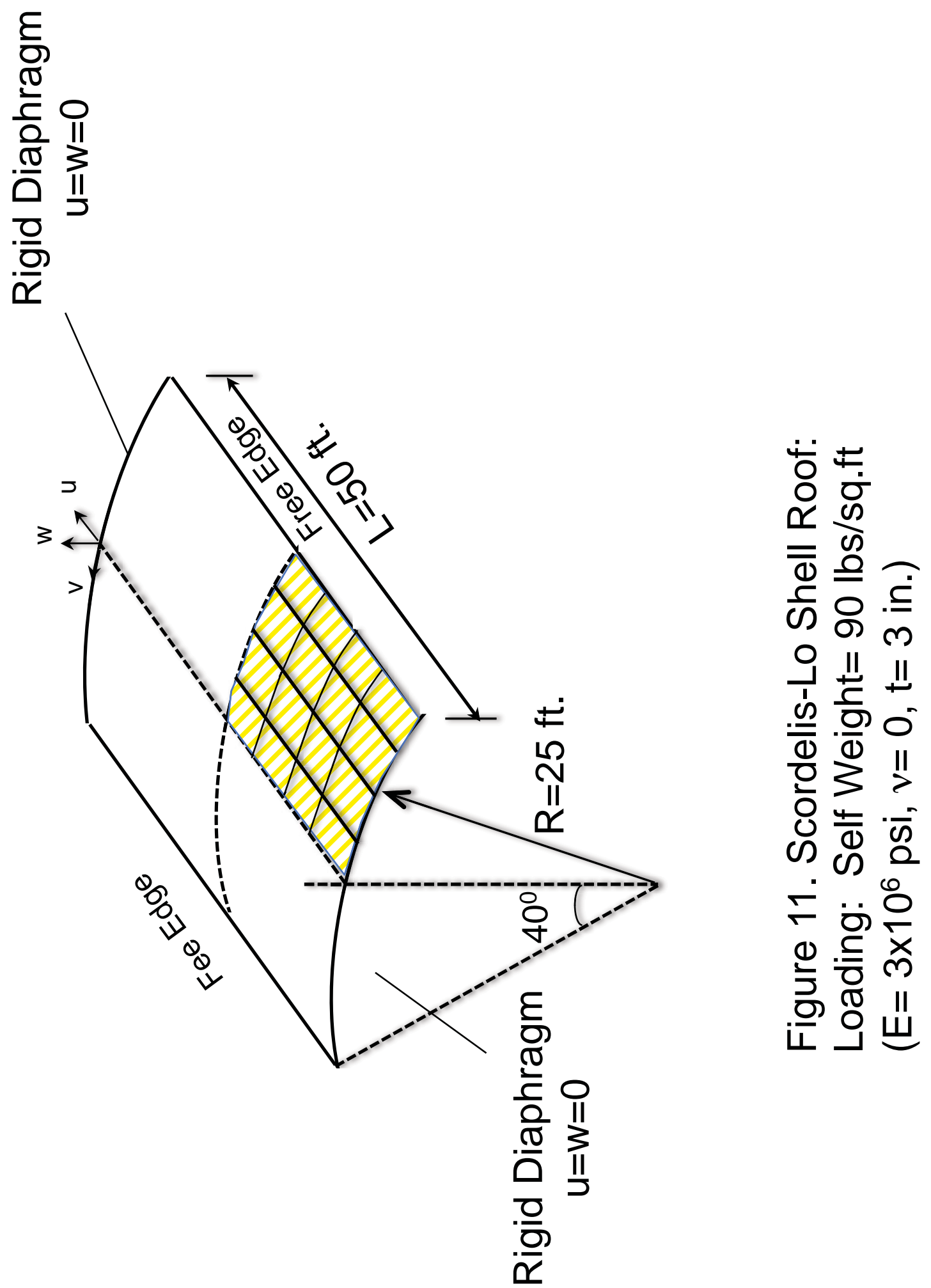


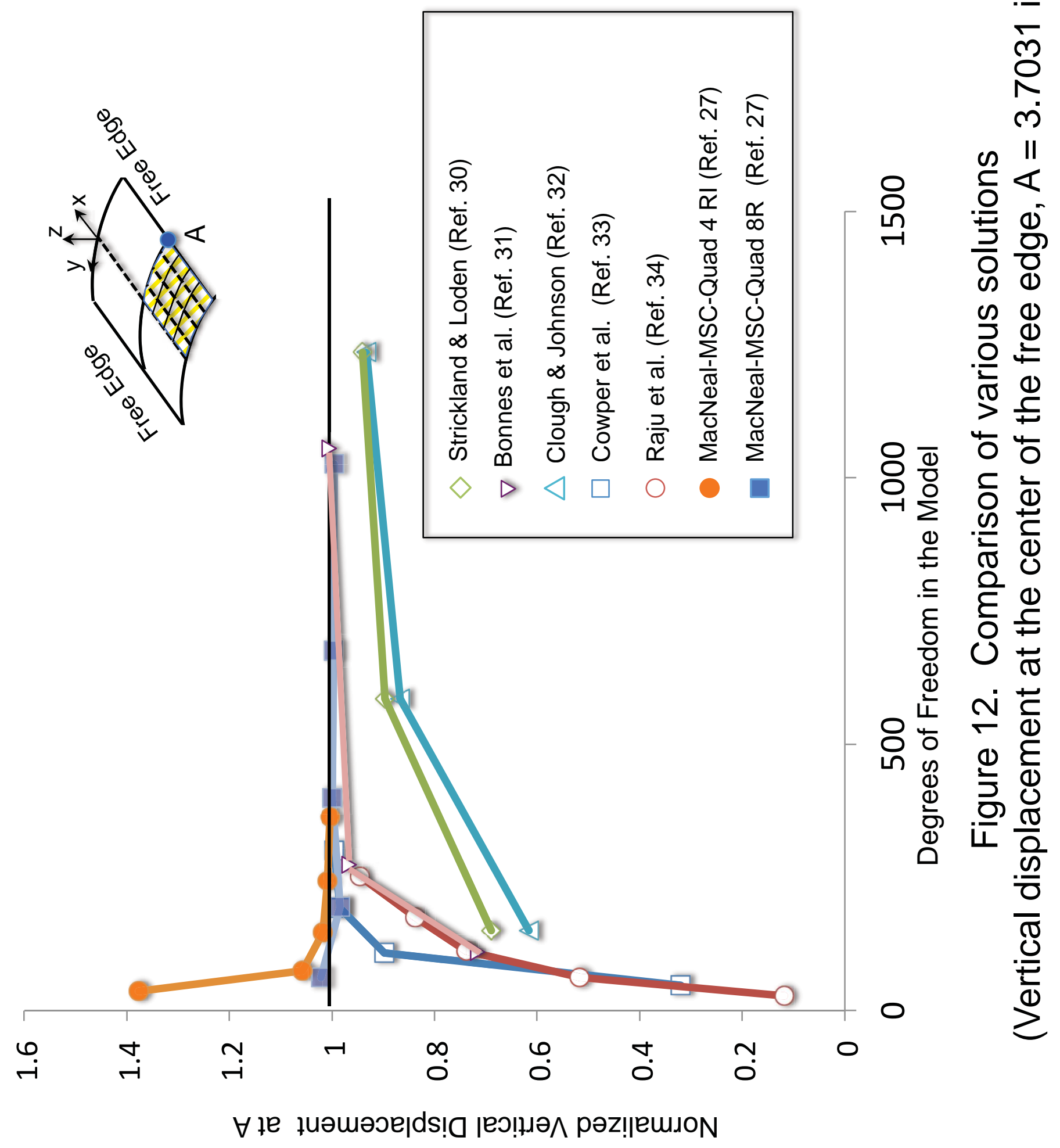



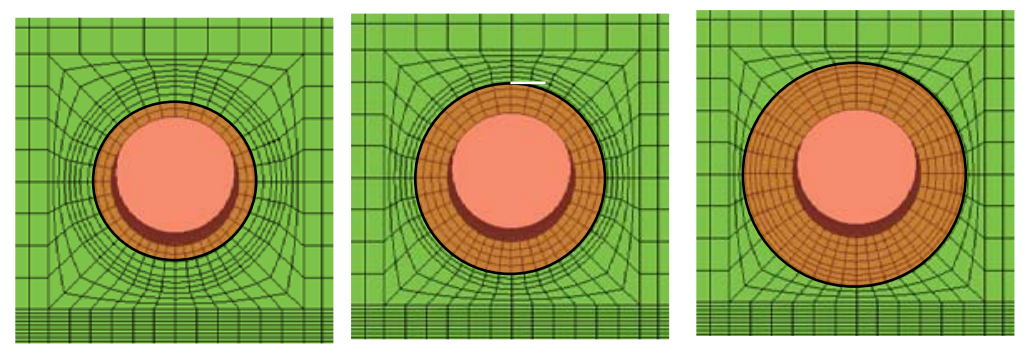

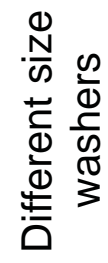
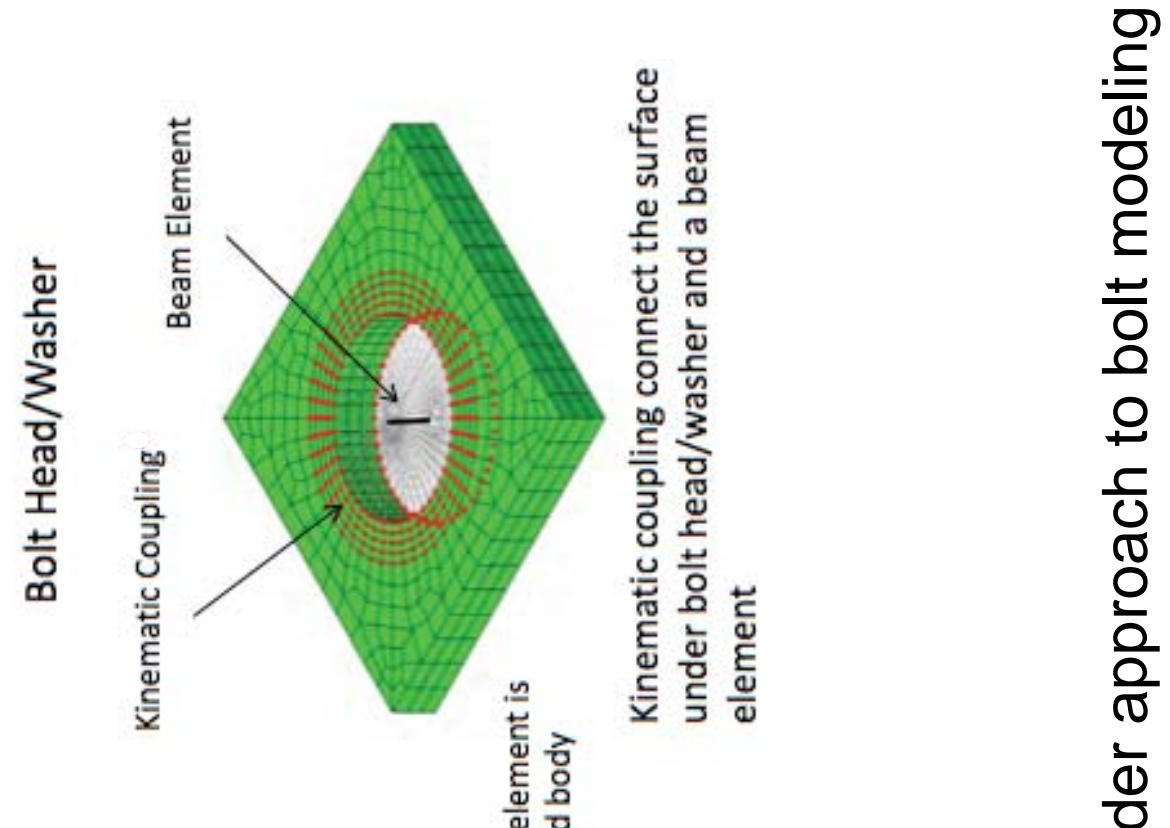

$\frac{\frac{1}{0}}{\frac{0}{0}}$

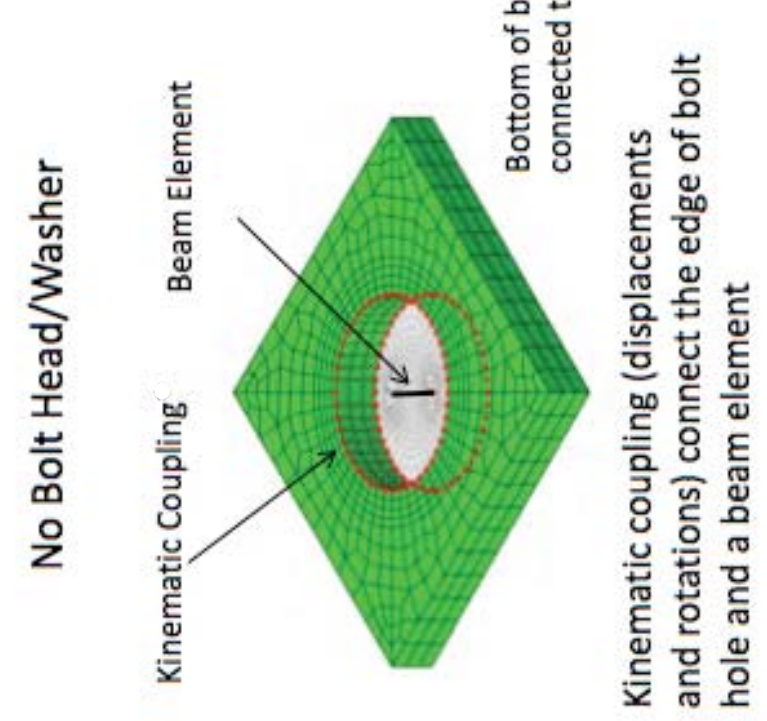

드

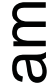

๓

ம்

(1)

흠ํำ 


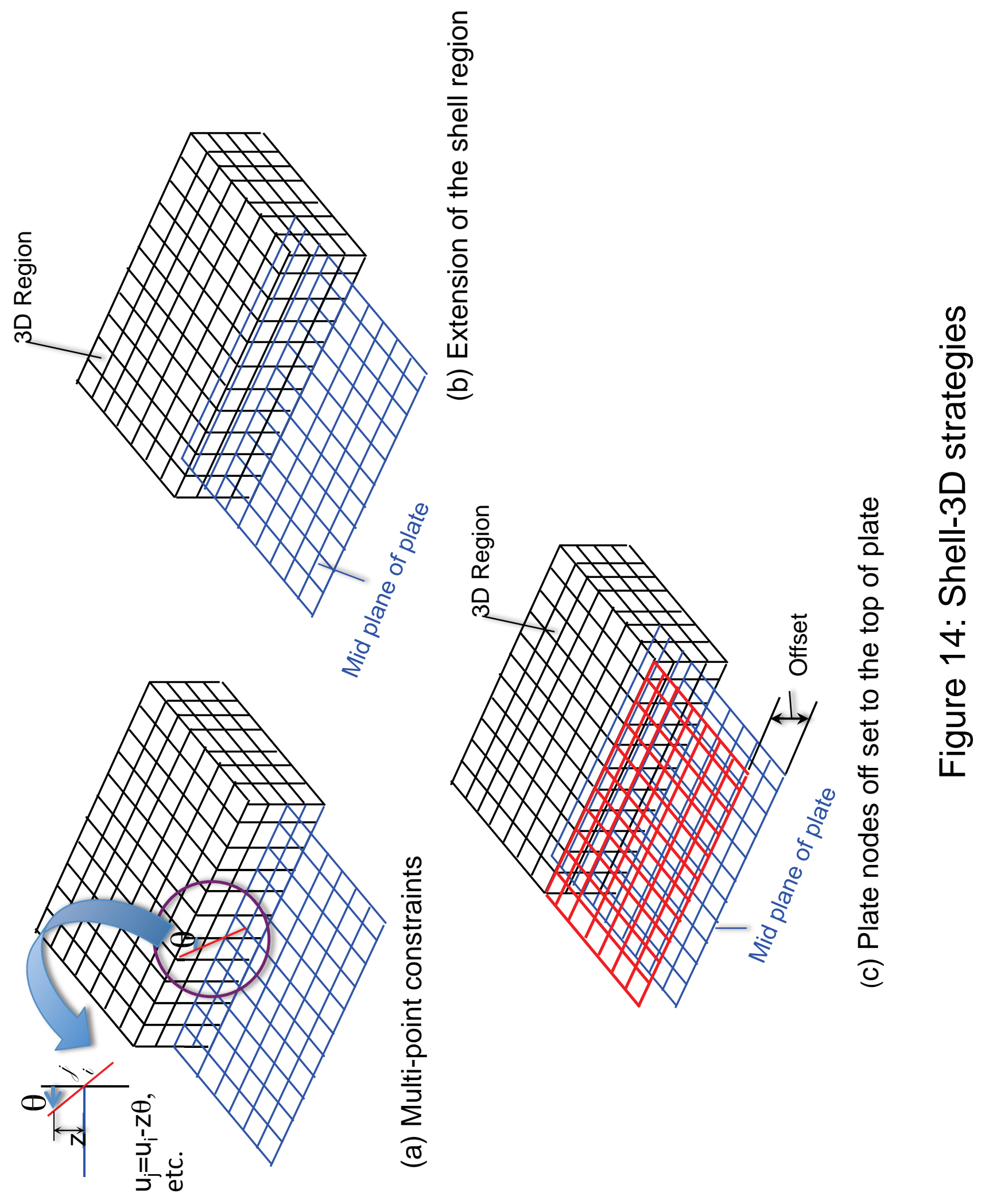



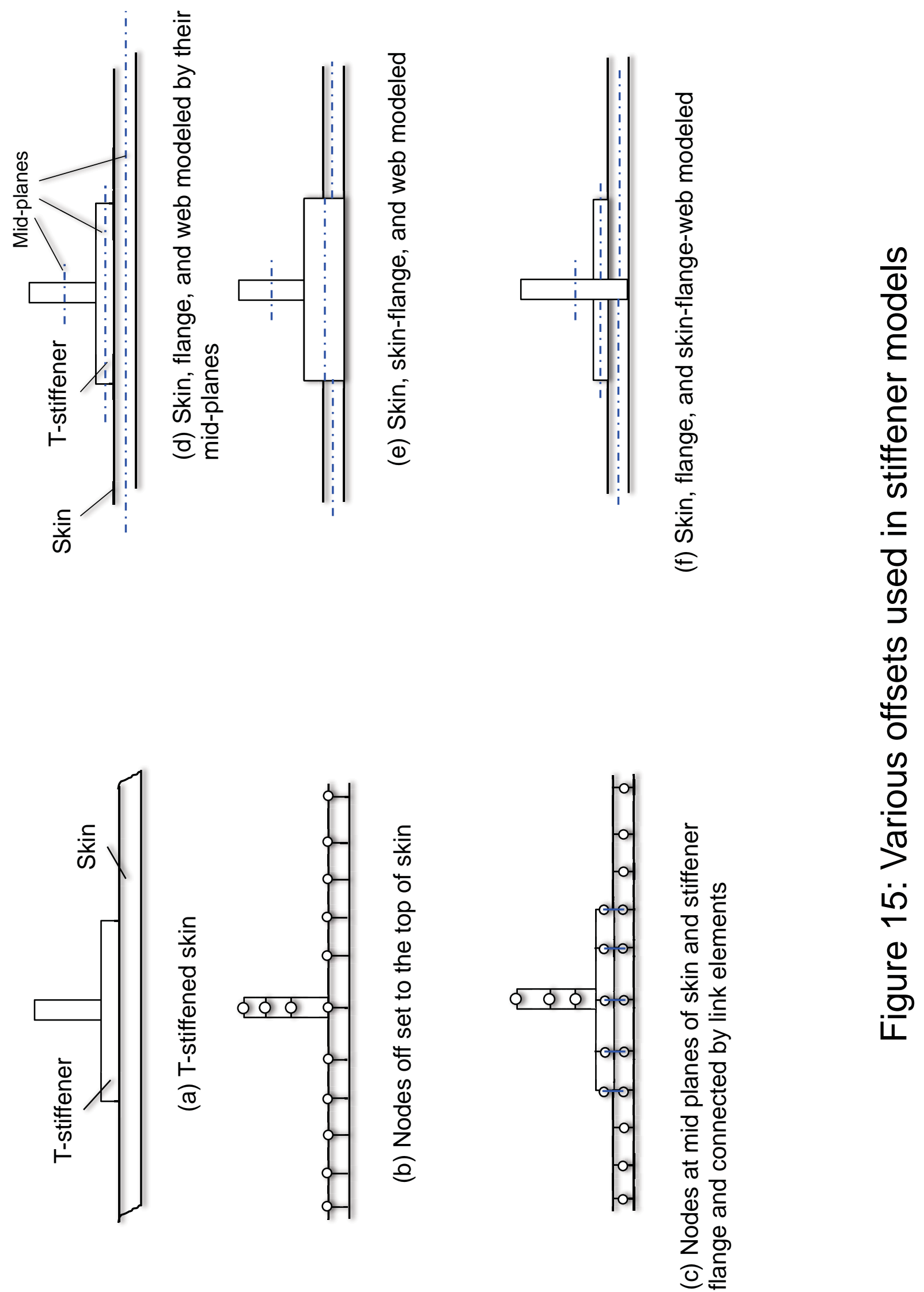